\title{
Multifunctional role of astrocytes as gatekeepers of neuronal energy supply
}

\author{
Jillian L. Stobart ${ }^{1,2 *}$ and Christopher M. Anderson ${ }^{1}$ \\ Division of Neurodegenerative Disorders, Department of Pharmacology and Therapeutics, St. Boniface Hospital Research, University of Manitoba, Winnipeg, \\ MB, Canada \\ ${ }^{2}$ Department of Nuclear Medicine, Institute of Pharmacology and Toxicology, University of Zürich, Zürich, Switzerland
}

Edited by:

Keith Murai, McGill University,

Canada

Reviewed by:

Carole Escartin, MIRCen, France

Keith Murai, McGill University,

Canada

*Correspondence:

Jillian L. Stobart, Department of

Nuclear Medicine, Institute of

Pharmacology and Toxicology,

University of Zürich, Rämistrasse

100, Universitätspital E Nuk-4,

$\mathrm{CH}-8091$ Zürich, Switzerland.

e-mail: jstobart@pharma.uzh.ch
Dynamic adjustments to neuronal energy supply in response to synaptic activity are critical for neuronal function. Glial cells known as astrocytes have processes that ensheath most central synapses and express G-protein-coupled neurotransmitter receptors and transporters that respond to neuronal activity. Astrocytes also release substrates for neuronal oxidative phosphorylation and have processes that terminate on the surface of brain arterioles and can influence vascular smooth muscle tone and local blood flow. Membrane receptor or transporter-mediated effects of glutamate represent a convergence point of astrocyte influence on neuronal bioenergetics. Astrocytic glutamate uptake drives glycolysis and subsequent shuttling of lactate from astrocytes to neurons for oxidative metabolism. Astrocytes also convert synaptically reclaimed glutamate to glutamine, which is returned to neurons for glutamate salvage or oxidation. Finally, astrocytes store brain energy currency in the form of glycogen, which can be mobilized to produce lactate for neuronal oxidative phosphorylation in response to glutamatergic neurotransmission. These mechanisms couple synaptically driven astrocytic responses to glutamate with release of energy substrates back to neurons to match demand with supply. In addition, astrocytes directly influence the tone of penetrating brain arterioles in response to glutamatergic neurotransmission, coordinating dynamic regulation of local blood flow. We will describe the role of astrocytes in neurometabolic and neurovascular coupling in detail and discuss, in turn, how astrocyte dysfunction may contribute to neuronal bioenergetic deficit and neurodegeneration. Understanding the role of astrocytes as a hub for neurometabolic and neurovascular coupling mechanisms is a critical underpinning for therapeutic development in a broad range of neurodegenerative disorders characterized by chronic generalized brain ischemia and brain microvascular dysfunction.

Keywords: astrocytes, brain oxidative metabolism, glutamate-glutamine shuttle, neurovascular coupling, Alzheimer's disease, ischemia, epilepsy

\section{INTRODUCTION}

The brain receives $10 \%$ of cardiac output but consumes $20 \%$ of total blood glucose and oxygen during cerebral activity to restore ion gradients after action potential conduction and neurotransmission (Magistretti et al., 1999; Magistretti, 2006). Large metabolic demand requires that brain blood flow remain constant despite variations in blood pressure (autoregulation) and that areas of high neuronal activity have correspondingly high metabolic rate and local blood supply (Magistretti, 2006). Astrocytes are multi-functional regulators of neurometabolic coupling that control uptake and release of neurotransmitters (Anderson and Swanson, 2000), influence local blood supply (Zonta et al., 2003; Mulligan and Macvicar, 2004; Takano et al., 2006; Gordon et al., 2008), and directly supply neurons with substrates for oxidative phosphorylation (Pellerin et al., 1998a).

Several characteristics of astrocytes confer suitability for sensing and satisfying neuronal metabolic needs. Protoplasmic astrocytes are highly organized into nearly unique three-dimensional domains (Oberheim et al., 2006) with limited overlap (Ogata and
Kosaka, 2002). This feature places astrocytes non-randomly in virtually all central nervous system (CNS) 3D space, which is an ideal anatomical scenario for cells engaging in regional brain activity monitoring and/or corresponding nutritive distribution. Astrocyte process extensions from the soma define domain extremities and extensively ensheath central synapses (Ventura and Harris, 1999) producing a synaptic structure referred to as the "tripartite synapse" (Araque et al., 1999; Oberheim et al., 2006), in which astrocyte processes are located in close enough proximity to communicating nerve terminals that they receive neurotransmitter input. Astrocyte processes also envelop parenchymal brain arterioles and capillaries in unique spatial domains, extending terminal structures known as endfeet that are directly in contact with the vascular basal lamina (Simard et al., 2003; Oberheim et al., 2006). Endfeet express surface proteins, such as glucose transporters, for uptake of energy substrates from the endothelium (Kacem et al., 1998), and are capable of releasing transmitters that influence local blood flow (Simard et al., 2003; Zonta et al., 2003; Mulligan and Macvicar, 2004; Metea and Newman, 2006; 
Gordon et al., 2008). Astrocytes are therefore also uniquely positioned for bidirectional communication across the blood-brain barrier, as well as being participants in synaptic transmission. In addition, single hippocampal or cortical astrocytes are in contact with up to 600 dendrites (Halassa et al., 2007) and over 100,000 synapses (Bushong et al., 2002), and extend multiple processes to blood vessels (McCaslin et al., 2011). This provides a single-cell linkage between the locus of neuronal activity and sites that can leverage additional energy supply in an arrangement known as the neurovascular unit. This anatomy provides an astrocyte-mediated communication link for energy substrate transfer between blood supply and synaptic terminals (Tsacopoulos and Magistretti, 1996; Simard et al., 2003; Rouach et al., 2008).

Protoplasmic astrocytes also form a functional syncytium, where distal processes are connected by connexin gap junctions permitting diffusion of ions and metabolites between neighboring astrocytes (Giaume and McCarthy, 1996; Scemes et al., 1998). This creates a conduit for intercellular communication and flow of metabolites, but also allows intracellular communication through autocellular junctions between processes of the same cell (Wolff et al., 1998; Rouach et al., 2002). Connexin proteins also form hemichannels, which do not connect to adjacent cells, but allow release of small molecules from the cytoplasm into the extracellular space (Contreras et al., 2002; Rouach et al., 2002; Ye et al., 2003). This network of gap junctions is central to astrocyte function and control of brain metabolism, facilitating communication and movement of molecules within and around astrocyte domains.

Peri-synaptic or vascular astrocyte distributions would not be functionally relevant without mechanisms for receiving input. Astrocytes achieve this by expressing numerous types of neurotransmitter receptors that initiate electrically silent activation of astrocytes by enhancing intracellular $\mathrm{Ca}^{2+}$ levels. These broad receptor categories are coupled to G-proteins and activate a wide array of intracellular second messenger pathways, including inositol trisphosphate production and release of $\mathrm{Ca}^{2+}$ into the cytoplasm from endoplasmic reticulum stores (Sheppard et al., 1997; Idestrup and Salter, 1998). This permits astrocytes to respond to synaptic transmission through elevated cytosolic $\mathrm{Ca}^{2+}$. Astrocyte GPCR receptors involved in $\mathrm{Ca}^{2+}$ signaling cover a diverse range of neurotransmitters such as $\mathrm{GABA}_{B}$ receptors (Kang et al., 1998; Bettler et al., 2004; Meier et al., 2008), acetylcholine muscarinic receptors (Takata et al., 2011; Navarrete et al., 2012), $\alpha$-adrenergic receptors (Duffy and Macvicar, 1995; Bekar et al., 2008), H1 histamine receptors (Shelton and McCarthy, 2000), endocannabinoid receptors (Navarrete and Araque, 2008, 2010), purinergic P2Y receptors binding adenine nucleotides (Guthrie et al., 1999), and metabotropic glutamate receptors (mGluRs) (Porter and McCarthy, 1996; Perea and Araque, 2007). Many papers implicate mGluR5 as a major activator of astrocyte $\mathrm{Ca}^{2+}$ (Bezzi et al., 1998; Zonta et al., 2003; Takano et al., 2006; Gordon et al., 2008; Liu et al., 2011), however, there is recent work suggesting mGluR5 expression decreases with age and does not stimulate $\mathrm{Ca}^{2+}$ signals in adult cortical and hippocampal astrocytes (Sun et al., 2013). More work on this is required before a consensus can be reached.

$\mathrm{Ca}^{2+}$ elevations may represent the fulcrum of a multi-faceted repertoire of potential astrocyte responses to sensory input.
There is broad consensus that increased astrocytic intracellular $\mathrm{Ca}^{2+}$ triggers release of gliotransmitters such as glutamate, ATP, and D-serine (Bezzi et al., 2004; Mothet et al., 2005; Jourdain et al., 2007). Gliotransmitters, in turn, can affect synaptic activity (Parpura et al., 1994; Araque et al., 1999; Panatier et al., 2006; Henneberger et al., 2010; Sasaki et al., 2011; Fossat et al., 2012), produce constriction or dilation of local blood supply vessels (Zonta et al., 2003; Mulligan and Macvicar, 2004; Takano et al., 2006; Gordon et al., 2008) or have an autocrine effect to amplify $\mathrm{Ca}^{2+}$ signals (Suadicani et al., 2006). Additionally, elevation of $\mathrm{Ca}^{2+}$ in a single astrocyte is capable of initiating a similar response in surrounding astrocytes in a regenerative wavelike fashion. This process is primarily dependent on connexin 43 (Scemes et al., 1998; Blomstrand et al., 1999; Haas et al., 2006; Gosejacob et al., 2011) and release of extracellular gliotransmitters, including ATP (Hassinger et al., 1996; Guthrie et al., 1999) and may mediate fast, long-distance intercellular communication between astrocytes (Scemes and Giaume, 2006). It is important to note that recent data challenge the view that astrocyte $\mathrm{Ca}^{2+}$ modulates neuronal activity (Petravicz et al., 2008; Agulhon et al., 2010; Nedergaard and Verkhratsky, 2012) or even that adult astrocytes express $\mathrm{Ca}^{2+}$-mobilizing metabotropic glutamate receptors shown previously to be critical for synaptic effects of astrocytes (Sun et al., 2013). These findings are fueling debate about the functional roles of astrocytic $\mathrm{Ca}^{2+}$ responses in adult animals in vivo. Finer spatial resolution of astrocytic $\mathrm{Ca}^{2+}$ levels may reveal that local responses are limited to process microdomains and not necessarily the cell soma (Shigetomi et al., 2010, 2012; Di Castro et al., 2011), which could partially explain apparent discrepancies. Regional differences in astrocytic physiology and developmental changes in astrocytic expression of neurotransmitter receptors may also be factors. Systematic attention to animal age, brain regions imaged and spatial resolution of astrocyte $\mathrm{Ca}^{2+}$ imaging in vivo will greatly help resolve these issues.

Architectural organization, neurotransmitter receptor expression, and gliotransmitter release are features enabling astrocytes to be prime regulators of synaptic environment and transmission (Araque et al., 1999; Anderson and Swanson, 2000; Henneberger and Rusakov, 2010), neurovascular coupling (Zonta et al., 2003; Mulligan and Macvicar, 2004; Takano et al., 2006; Gordon et al., 2008), blood-brain barrier function (Ballabh et al., 2004) and carbon source shuttling to neurons in high demand periods (Pellerin et al., 1998a; Rouach et al., 2008). We will discuss the influence of astrocytes on the synaptic environment and cerebral bioenergetics, including how astrocytes handle glutamate, supply neurons with oxidative energy substrates and store glycogen. Mechanisms by which astrocytes couple glutamatergic neurotransmission with neuronal energy metabolism and blood flow regulation will also be discussed. Finally, we will survey astrocyte dysfunction in brain diseases and injuries, including ischemic stroke, epilepsy, and Alzheimer's Disease.

\section{ASTROCYTES CONTROL CEREBRAL GLUTAMATE LEVELS}

Glutamate is quantitatively the dominant excitatory CNS neurotransmitter (Fonnum, 1984). Unregulated synaptic glutamate levels, however, can cause neuronal excitatory cell death in multiple diseases (Dong et al., 2009). Therefore, regulation of 
synaptic glutamate is crucial. Under normal conditions, glutamate balance in the neuropil is tightly controlled by astrocytes. Astrocytic processes enveloping glutamatergic synapses express active amino acid transport proteins that are the main route of extracellular glutamate removal (Rothstein et al., 1994; Danbolt, 2001). The primary glutamate transporters are $\mathrm{Na}^{+}$/glutamate co-transporters of the SLC gene family, termed excitatory amino acid transporter 1 and 2 (EAAT1 and 2) in human tissue (Shashidharan et al., 1994) or glutamate transporter-1 (GLT-1) and L-glutamate/L-aspartate transporter (GLAST) in rodents (Pines et al., 1992; Storck et al., 1992). These proteins rely on the $\mathrm{Na}^{+}$electrochemical gradient, maintained by $\mathrm{Na}^{+} / \mathrm{K}^{+}$ATPase activity, to co-transport 1 glutamate molecule and $3 \mathrm{Na}^{+}$ions. Glutamate uptake is energetically expensive, as ATP is consumed by $\mathrm{Na}^{+} / \mathrm{K}^{+}$ATPases, but with sufficient energy supply, perisynaptic astrocyte processes prevent excitotoxic accumulation of glutamate in the neuropil. $\mathrm{A} \mathrm{Na}^{+}$-independent, glutamate/cystine antiporter is also expressed by astrocytes but this is considered a secondary mechanism of glutamate uptake as these transporters primarily conduct cystine (Cho and Bannai, 1990).

Neurons may also take up glutamate through EAAT3 (EAAC1 in rodents) (He et al., 2000; Chen and Swanson, 2003), EAAT4 (Furuta et al., 1997; Nagao et al., 1997; Jackson et al., 2001), or EAAT5 (Arriza et al., 1997); however, the expression and localization of these transporters vary throughout the brain. For example, EAAT5 is mainly located in the retina (Arriza et al., 1997) and EAAC1 and EAAT4 are found on extrasynaptic neuronal membranes, particularly in the cerebellum, and are believed to modulate glutamate release and post-synaptic excitation (Tong and Jahr, 1994; Overstreet et al., 1999). EAAT3 also readily takes up cysteine (Chen and Swanson, 2003), which is used for glutathione production, suggesting EAAT3 has a central role in neuronal antioxidant defense (Aoyama et al., 2006).

Once synaptic glutamate enters astrocytes, one-third is used as a substrate for oxidative metabolism (Schousboe et al., 1993; Hertz and Zielke, 2004; Hertz et al., 2007). Glutamate can be converted to $\alpha$-ketoglutarate by glutamate dehydrogenase or aspartate aminotransferase to replenish components of the tricarboxylic acid (TCA) cycle (Faff-Michalak and Albrecht, 1993; McKenna et al., 2006a). An additional portion of salvaged glutamate is recycled for neurotransmission through a process known as the glutamate-glutamine shuttle (Figure 1). Glutamate is converted to glutamine by astrocytic glutamine synthase (MartinezHernandez et al., 1977). Glutamine is then transported from the astrocytic cytoplasm by system $\mathrm{N}$ transporters and removed from the extracellular space by neuronal system A neutral amino acid transporters (Chaudhry et al., 2002). Neuronal glutamine is converted back to glutamate by phosphate-activated glutaminase (Kvamme et al., 2000) and repackaged into vesicles (Fremeau et al., 2004) for synaptic release (McKenna, 2007). This shuttle process is vital for proper synaptic glutamate release because neurons do not express enzymes for de novo synthesis of glutamate, so neuronal glutamate is entirely derived from astrocyte glutamine or $\alpha$-ketoglutarate (Yu et al., 1983; Shank et al., 1985). Astrocytes produce de novo glutamate or glutamine from glucose via pyruvate conversion to oxaloacetate by pyruvate carboxylase (Yu et al., 1983; Hertz, 2011).

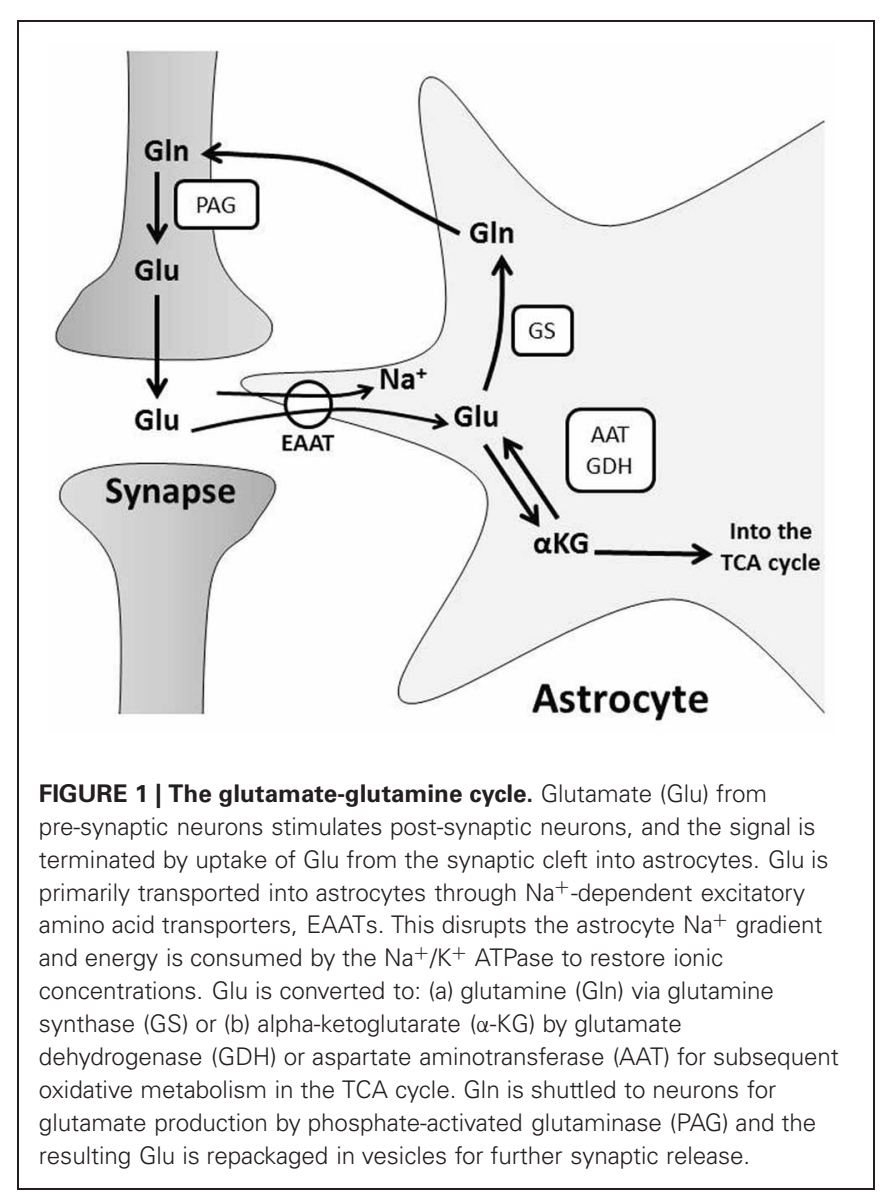

The glutamate-glutamine cycle not only drives neurotransmitter recycling, but also influences brain metabolism. Astrocytes metabolize glutamate to TCA cycle intermediates (Schousboe et al., 1993; Hertz and Zielke, 2004; Hertz et al., 2007), which diminishes the glutamate pool, and may drive astrocytic glucose consumption, ATP production and de novo glutamate synthesis (Hertz, 2011). Neurons also utilize glutamine and/or glutamate as energy substrates during glucose deprivation in vitro (Peng et al., 2007) or ischemia in vivo (Pascual et al., 1998). They similarly use glutamine or glutamate to replenish intermediates of the TCA cycle during metabolism of other substrates in vitro (Shokati et al., 2005). These observations suggest that the glutamateglutamine shuttle impacts neuronal metabolism. Glutamate uptake by cultured astrocytes also correlates with increased glycolysis and lactate production (Pellerin and Magistretti, 1994). This is a separate mechanism of glutamate-driven astrocyteneuron metabolic coupling that will be discussed below.

\section{ASTROCYTE LACTATE FUELS NEURONAL METABOLISM}

Synaptic glutamate is a direct signal of neuronal activity and, therefore, of metabolic demand. Astrocytes surveying synaptic activity respond with elevated glucose utilization, glycolysis (Pellerin and Magistretti, 1994; Cholet et al., 2001), and lactate production (Pellerin and Magistretti, 1994; Schurr et al., 1999; Voutsinos-Porche et al., 2003; Caesar et al., 2008). Enhanced astrocytic metabolism is thought to result from intracellular 
$\mathrm{Na}^{+}$accumulation associated with $\mathrm{Na}^{+}$/glutamate co-transport (Voutsinos-Porche et al., 2003; Langer and Rose, 2009). This elevates ATP consumption by $\mathrm{Na}^{+} / \mathrm{K}^{+}$ATPase activity resulting in increased glucose uptake, enhanced glycolytic rate, and lactate generation (Pellerin and Magistretti, 1994; Chatton et al., 2000; Loaiza et al., 2003; Porras et al., 2008). Intercellular $\mathrm{Na}^{+}$waves are also generated throughout the astrocyte syncytium, elevating glucose uptake, and metabolism in neighboring astrocytes as well (Bernardinelli et al., 2004; Scemes and Giaume, 2006). Furthermore, $\mathrm{K}^{+}$released during neurotransmission is taken up by astrocytes, which stimulates glycolysis and lactate export (Bittner et al., 2011; Ruminot et al., 2011).

Glutamatergic neurotransmission increases both neuronal and astrocytic energy consumption, but the primary neuronal energetic substrate during normal and pathological conditions has been debated. One hypothesis is that neurons and astrocytes utilize systemically delivered glucose and oxygen from the extracellular space for metabolism by oxidative phosphorylation (Chih and Roberts, 2003). The second hypothesis proposes astrocytes convert glucose to lactate in an activity-dependent, glutamate-mediated manner for delivery to neurons (Pellerin and Magistretti, 1994; Pellerin et al., 1998a; Magistretti and Pellerin, 1999). This is known as the astrocyte-neuron lactate shuttle hypothesis (ANLSH) and suggests lactate is more than a potentially damaging final metabolite of anaerobic glycolysis (Figure 2; Kasischke, 2008).

In light of the ANLSH, a large body of literature pertaining to production and neuronal use of lactate has accumulated over the last 20 years. Several points have been made. First,

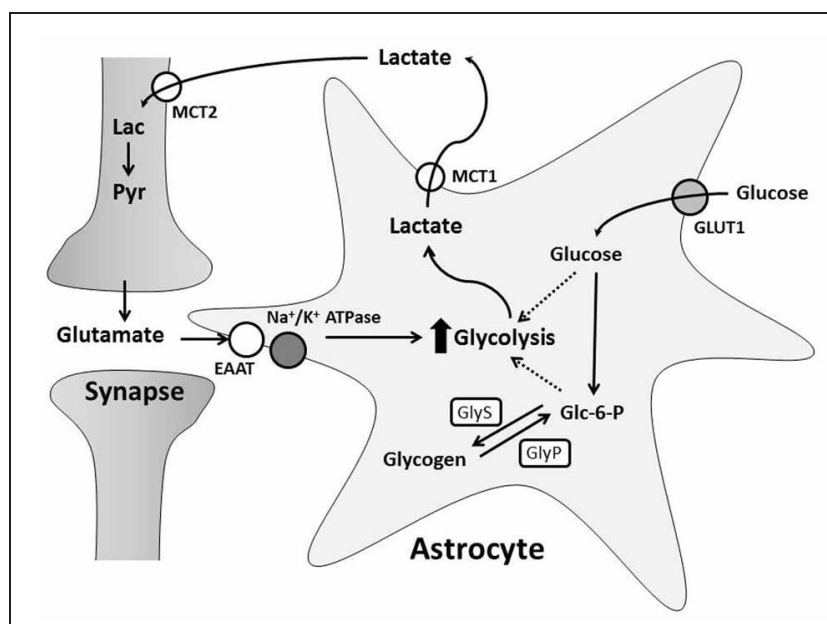

FIGURE 2 | The Astrocyte to Neuron Lactate Shuttle Hypothesis. Free glucose is taken up by astrocytes through GLUT1 transporters and converted to glucose-6-phosphate (Glc-6-P). Glc-6-P is stored as glycogen synthesized by glycogen synthase (GlyS). During greater energy demand, glycogenolysis, mediated by glycogen phosphorylase (GlyP), creates Glc-6-P for glycolysis. Synaptic transmission induces astrocyte glycolysis and lactate production through glutamate uptake. This increases glucose consumption and/or glycogen breakdown in astrocytes. Astrocyte lactate is transported into the extracellular space by MCT1 and taken up through MCT2 by neurons. Neurons can convert lactate (Lac) to pyruvate (Pyr) for oxidative phosphorylation. there is a correlation between synaptic activity and extracellular lactate concentrations. At rest, the extracellular space around neurons and astrocytes has a homogenous concentration of lactate and glucose (Simpson et al., 2007; Barros and Deitmer, 2010). Extracellular lactate decreases slightly during short periods of brain activation in vivo ( $\mathrm{Hu}$ and Wilson, 1997; Mangia et al., 2003), possibly because neurons are utilizing lactate for oxidative metabolism (Kasischke et al., 2004). However, extracellular lactate rapidly rises as neuronal stimulation continues for longer periods (Prichard et al., 1991; Mangia et al., 2007). Oxygen levels remain unchanged, suggesting brain activation stimulates aerobic glycolysis ( $\mathrm{Hu}$ and Wilson, 1997). Second, in vitro studies demonstrate that glutamate induces glucose transporter (GLUT1) activity and uptake rates in astrocytes (Loaiza et al., 2003), while inhibiting neuronal glucose transporter activity (Porras et al., 2004). This suggests glutamatergic transmission may increase astrocyte glucose availability and reduce neuronal glucose metabolism. Third, lactate can support neuronal survival. In rodent brain slices, inhibition of lactate transport and glycolysis during exposure to glutamate caused a permanent loss of neuronal function (Schurr et al., 1999), while addition of lactate maintained synaptic activity in the absence of glucose (Schurr et al., 1988; Fowler, 1993; Izumi et al., 1997), preventing neurotoxicity (Schurr et al., 1997; Maus et al., 1999; Cater et al., 2001). Fourth, neurons express protein machinery necessary for lactate metabolism. Lactate metabolism is mediated by lactate dehydrogenase (LDH), which reversibly converts pyruvate to lactate with oxidation of NADH to $\mathrm{NAD}^{+}$(Tsacopoulos and Magistretti, 1996). Several different LDH isoforms are located in the brain; LDH1 is the main isoform in neurons, while LDH1 and LDH5 are found in astrocytes (Bittar et al., 1996; Tsacopoulos and Magistretti, 1996). Lactate consumption is favored by neuronal LDH1, which promotes conversion of lactate to pyruvate (Bittar et al., 1996). In contrast, there is evidence that astrocytes favor production of lactate (Walz and Mukerji, 1988; Peng et al., 1994), likely due to the properties of LDH5, which has a higher affinity for pyruvate than lactate (Bittar et al., 1996). Lactate is transported between the intracellular and extracellular spaces by monocarboxylate transporters (MCT). MCT are symporters that co-transport lactate anions with $\mathrm{H}^{+}$, suggesting lactate transport is driven by $\mathrm{pH}$ (Schneider et al., 1993; Barros and Deitmer, 2010). The distribution of MCTs in the brain is heterogeneous: MCT1, MCT2, and MCT4 are expressed by astrocytes, while neurons express predominately MCT2 (Broer et al., 1997; Gerhart et al., 1998; Pellerin et al., 1998b; Bergersen et al., 2001; Pierre et al., 2002). MCT2 co-localizes with post-synaptic density proteins in dendritic spines and has the highest affinity for lactate of all MCTs (Bergersen et al., 2001). Together, MCT2 and LDH1 provide neurons with lactate protein machinery ideally suited to remove and metabolize lactate from active synapses. Lastly, a recent study found that an important activator of glycolysis, 6-phosphofructo-2-kinase/fructose 2,6-bisphosphatase isoform 3 (Pfkfb3), is continually degraded in neurons (Herrero-Mendez et al., 2009). This suggests glucose metabolism is shifted toward the pentose phosphate pathway and antioxidant production, and that neurons have a low glycolytic rate, necessitating utilization of lactate for aerobic respiration. 
There is also a correlation between changes in neuronal and astrocytic redox states and lactate transport and metabolism that may support the ANLSH (Hirrlinger and Dringen, 2010). During glycolysis, cytosolic $\mathrm{NADH}$ is produced and must be oxidized back to $\mathrm{NAD}^{+}$in order for glycolysis to continue. $\mathrm{NAD}^{+}$is replenished by lactate production or redox shuttle systems (glycerol-3-phosphate and malate-aspartate shuttle, MAS) which transfer reducing equivalents to the mitochondrial electron transport complexes. While the level of involvement of the glycerol-3-phoshpate shuttle in neuronal $\mathrm{NAD}^{+}$homeostasis is not clear (Cammer and Zimmerman, 1982; Waagepetersen et al., 2001; Nguyen et al., 2003), the MAS is important for regenerating $\mathrm{NAD}^{+}$for glutamate neurotransmitter renewal and energy metabolism (Palaiologos et al., 1988; McKenna et al., 2006b). Inhibition of the MAS-elevated cytosolic NADH, disrupting the redox balance and limiting lactate consumption (McKenna et al., 2006b) without affecting glucose metabolism in synaptic terminals (McKenna et al., 1993). Moreover, disruption of the MAS in malate-aspartate carrier (aralar) deletion mice resulted in impaired neuronal development (Gomez-Galan et al., 2012), reduced dopamine levels (Llorente-Folch et al., 2013), and hypomyelination (Ramos et al., 2011), indicating this pathway affects neuronal function in a profound way. There is no clear evidence that this is related to lactate metabolism, however.

The role of the malate-aspartate shuttle in astrocytes is currently debated. Several groups show that astrocytes express low levels of aralar (Ramos et al., 2003; Berkich et al., 2007), which limits MAS activity and requires elevated lactate production to replenish cytosolic $\mathrm{NAD}^{+}$(Schurr, 2006; Lemire et al., 2008). In support, astrocyte lactate-to-pyruvate ratios were unchanged in aralar knockout mice, compared to wild type controls (Pardo et al., 2011). In contrast, a recent paper suggests adult cultured astrocytes express aralar and the MAS could be functional (Li et al., 2012). This makes the importance of MAS in astrocytes difficult to determine at this point. Nevertheless, there is a clear correlation between cytosolic redox states and lactate production in astrocytes. In cultured astrocytes, inhibition of oxidative phosphorylation (which elevates cytosolic NADH) increases lactate production and regenerates $\mathrm{NAD}^{+}$(Dringen et al., 1993). High levels of NADH also influence transcription factors, including Clock and NPAS2, which activate LDH1 expression in astrocytes (Rutter et al., 2001), further potentiating lactate production. Again, extracellular lactate increases during longer periods of neuronal stimulation $(\sim 10 \mathrm{~s})$, and a corresponding elevation of astrocytic cytosolic NADH concentrations is also observed (Kasischke et al., 2004). This means astrocytes may replenish extracellular lactate pools for shuttling to neurons during prolonged activation (Pellerin et al., 1998a; Magistretti and Pellerin, 1999; Magistretti et al., 1999; Bouzier-Sore et al., 2002).

Mathematical modeling has been used to approximate the flux of energy metabolites between neurons and astrocytes based on known mass balances and enzyme/transporter kinetics, with the goal of linking in vitro, in vivo, and functional imaging results. Several models have recently been presented, but with varying results. One model describes energy substrates (lactate, glucose, pyruvate), oxygen, and $\mathrm{NADH}$ concentrations within the neuronal and astrocyte energy compartments, while also considering the subcellular compartments (cytosol and mitochondria) (Aubert et al., 2007), glutamate transport, and astrocyte glycogen (Cloutier et al., 2009). Results from this model support the ANLSH (Aubert et al., 2007; Cloutier et al., 2009) and the flow of lactate from astrocytes to neurons. The second model focuses on glucose and lactate transport between the blood-brain barrier, neurons, and astrocytes and suggests that neurons primarily metabolize glucose and export lactate (Simpson et al., 2007; Mangia et al., 2009). This supports a neuron to astrocyte lactate shuttle hypothesis (NALSH) (Simpson et al., 2007; Mangia et al., 2009). A third model attempts to combine metabolism rates and concentrations from the first model with transporter kinetics and metabolite diffusion equations from the second model and the results also support a neuron to astrocyte lactate shuttle (Dinuzzo et al., 2010). While the outcomes and design of these mathematical models continue to be debated, each model succeeds in raising questions to be addressed by future experiments. Most notably, there is evidence that neurons can utilize lactate as an energy source during periods of activation, but the question remains: do astrocytes produce lactate for neuronal consumption? Clearly, neurons and astrocytes produce and utilize lactate differently based on the expression profiles and properties of LDH and MCT isoforms, but due to experimental limitations of lactate detection, it is not possible to distinguish lactate producers from the cell type that utilizes lactate, or if these roles change depending on region or activity (Barros and Deitmer, 2010). Measurement of radiotracer kinetics in vivo suggest neurons consume lactate during activation (Wyss et al., 2011), and further in vivo studies may elucidate the complex flux of brain metabolites. In particular, experiments involving awake animals may more accurately reflect brain metabolic states, as anesthetics are known to decrease metabolic rates (Alkire et al., 1995, 1997, 1999). It would also be beneficial to directly visualize in vivo glucose and lactate levels (possibly via fluorescent sensors for glucose or lactate) to determine metabolite concentrations in different cell populations in various brain regions during activation (Barros et al., 2013; San Martin et al., 2013).

Astrocyte lactate is not only a potential energy substrate, but also acts as a signaling molecule in other brain bioenergetic processes, including blood flow regulation (discussed in detail later) (Gordon et al., 2008), blood glucose sensing (Lam et al., 2005, 2007), and sodium sensing in the subfornical organ (SFO; Shimizu et al., 2007). Brain lactate is involved in a brainliver signaling axis. Hypothalamic arcuate nuclei projections to the brainstem signal to vagal hepatic efferents (Schwartz et al., 2000; Grill et al., 2002) to regulate blood glucose levels (Lam et al., 2005) and insulin signaling (Pocai et al., 2005). Elevated blood glucose leads to increased glial glucose uptake (Chari et al., 2011) and lactate production in the rodent hypothalamus (Lam et al., 2005). Lactate is transported into hypothalamic neurons for conversion to pyruvate. This process is required to activate neuronal ATP-sensitive $\mathrm{K}^{+}$channels $\left(\mathrm{K}_{\mathrm{ATP}}\right)$ (Lam et al., 2005), and $\mathrm{K}^{+}$flux that induces hyperpolarization and reduces firing (Pocai et al., 2005). Resulting hepatic vagal stimulation (Pocai et al., 2005) reduces gluconeogenesis and glycogenolysis rates (Lam et al., 2005; Pocai et al., 2005), leading to secretion of verylow density lipoprotein (Lam et al., 2007) and reduced expression 
of hepatic enzymes for endogenous glucose production, including glucose-6-phosphatase (Lam et al., 2005; Pocai et al., 2005; Kishore et al., 2011). This provides a lactate-mediated brain-liver negative feedback axis (Lam et al., 2007), which has implications in obesity and hepatic insulin resistance. In particular, hypothalamic glial GLUT1 expression and glucose uptake are decreased during hyperglycemia in rodents in vivo, and this could form the basis of blood glucose dysregulation in diabetes (Chari et al., 2011). Also, intracerebroventricular injection of lactate decreased blood glucose levels in animal models of uncontrolled diabetes and diet-induced insulin resistance, independent of insulin signaling (Chari et al., 2008), which suggests that hypothalamic lactate could be a future therapeutic target.

In the SFO of the brain periventricular region, lactate influences salt intake behavior and blood $\mathrm{Na}^{+}$sensing (Shimizu et al., 2007). Glial cells of the SFO express atypical sodium $\left(\mathrm{Na}_{x}\right)$ channels (Hiyama et al., 2004), which have a concentrationsensitive, extracellular sodium threshold of $150 \mathrm{mM}$ (Hiyama et al., 2002). SFO glial $\mathrm{Na}_{x}$ channels interact with $\mathrm{Na}^{+} / \mathrm{K}^{+}$ ATPase and progressive $\mathrm{Na}^{+}$influx upon elevated extracellular $\mathrm{Na}^{+}$triggers anaerobic glucose metabolism and lactate production (Shimizu et al., 2007). Lactate and $\mathrm{Na}_{x}$ channels mediate salt-intake behavior, since $\mathrm{Na}_{x}$-knockout mice continue to ingest salt when dehydrated (Hiyama et al., 2004) and they have reduced SFO lactate concentrations compared to wild type animals (Shimizu et al., 2007). Salt-intake behavior is reduced when glial lactate stimulates inhibitory neurons in the SFO by a MCT-dependent mechanism (Shimizu et al., 2007). This mechanism may also involve inhibition of $\mathrm{K}_{\mathrm{ATP}}$ channels by lactateinduced ATP production (Shimizu et al., 2007); however, further experiments are required to determine the involvement of these channels in the pathway. These studies of the role of lactate in glucose and sodium sensing and food intake behaviors indicate an exciting new role for lactate as a signaling molecule to neurons and suggest the importance of lactate in the brain may be underestimated.

\section{ASTROCYTE GLYCOGEN PRODUCTION FUELS NEURONAL METABOLISM}

Glycogen is the main cellular storage depot of glucose in mammals (Brown and Ransom, 2007). When glucose is in excess of immediate energy requirements, it can be stored as glycogen; glycogen is mobilized to glucose when glucose levels cannot meet energy demands (Brown and Ransom, 2007). Astrocytes are the main glycogen repository in the adult brain (Phelps, 1972; Koizumi, 1974). Astrocytes express both glycogen synthase (GlyS, for glycogen formation) and glycogen phosphorylase (GlyP, for glycogen degradation) (Pellegri et al., 1996) and glycogen stores are primarily located in regions of high synaptic density, such as gray matter (Phelps, 1972; Sagar et al., 1987). Astrocyte glycogen is critical for maintaining neuronal survival and synaptic activity during hypoglycemia in vitro (Swanson and Choi, 1993) and in vivo in cortex, hippocampus (Suh et al., 2007) and optic nerve (Wender et al., 2000). Similarly, during periods of increased brain activity and local glucose depletion, astrocyte glycogen stores can be rapidly degraded to provide a temporary energy supply (Shulman et al., 2001; Brown et al., 2003, 2005).
Glycogen cycling occurs when astrocytes acquire glucose through the glucose transporter, GLUT1, and rapidly phosphorylate it to glucose 6-phosphate in the first steps of glycolysis, preventing it from leaving the cell (Vannucci et al., 1997). Glucose-6-phosphate can be converted to glycogen through a process catalyzed by GlyS (Figure 2). GlyS exists in both an inactive phosphorylated form and an active dephosphorylated form. Astrocyte glycogen formation is therefore regulated by enzymes that dephosphorylate and activate GlyS, most notably protein phosphatase 1 which acts via the regulatory subunit Protein Targeting to Glycogen (PTG) (Allaman et al., 2000). Expression of PTG is stimulated by numerous molecules such as vasoactive intestinal peptide, norepinephrine, and adenosine, which increase glycogen production (Sorg and Magistretti, 1992; Allaman et al., 2000). Similarly, GlyP can be regulated by phosphorylase kinase, which converts GlyP from its inactive form to its active, phosphorylated form (Brown and Ransom, 2007). GlyP is only expressed in astrocytes, solidifying the specialization of these cells in glycogen utilization. Glycogenolysis results in glucose-6-phosphate, which can be metabolized within astrocytes to lactate (Dringen and Hamprecht, 1993; Tekkok et al., 2005) or free glucose (Ghosh et al., 2005). This suggests astrocyte glycogen-derived substrates can be supplied to other brain cells for oxidative metabolism.

The astrocytic glycogen reservoir is dynamic under normal brain activity and euglycemic conditions (Brown et al., 2005), and is influenced by glutamatergic neurotransmission and uptake. Glutamate triggers glycogenolysis to meet the energy demand of the glutamate-glutamine cycle and $\mathrm{Na}^{+}$gradient restoration, in addition to the mechanisms proposed in the ANLSH (Shulman et al., 2001). Glycogenolysis fuels glutamate uptake by enhancing active transport-mediated recovery from the extracellular space, since inhibition of glycogenolysis-elevated extracellular glutamate concentrations (Sickmann et al., 2009; Schousboe et al., 2010). Glycogenolysis also facilitates de novo synthesis of glutamate and glutamine (Sickmann et al., 2005; Gibbs et al., 2006, 2007). Therefore, astrocyte glycogen is important for supporting the energetic needs of glutamatergic neurotransmission.

Recent studies have found glycogen-derived lactate is central to higher cognitive function and memory formation (Gibbs et al., 2006; Newman et al., 2011; Suzuki et al., 2011). In day old chicks, a bead discrimination learning task for memory consolidation was impaired after inhibition of glycogenolysis (Gibbs et al., 2006, 2007) or injection of poorly metabolized D-lactate (which competes with L-lactate for transport) (Gibbs and Hertz, 2008). An in vivo study of rats during an inhibitory avoidance test found learning-induced glycogenolysis and lactate release that was important for long-term memory formation (Suzuki et al., 2011). This was determined by administering inhibitors of glycogen phosphorylation or knocking down expression of MCT1/4 or MCT2, which induced amnesia. Inhibition of glycogen phosphorylation also reduced long-term potentiation (LTP), which was rescued by lactate injection (Suzuki et al., 2011). In another rat study during a spontaneous alternation task to assess spatial working short-term memory, lactate concentrations increased during the task and inhibition of glycogenolysis and lactate transport decreased task success (Newman et al., 2011). These results suggest astrocyte glycogenolysis and lactate transport to neurons 
is required for working memory processing and long-term memory consolidation.

While debate over the primary neuronal energy source will likely continue, it is clear that there is situational activitydependent regulation of neuronal metabolism by astrocytes involving glycogen cycling, lactate production, and the glutamateglutamine shuttle. This metabolic coupling of astrocytes and neurons appears to be important for higher cognitive function.

\section{ASTROCYTES MEDIATE VASOMOTOR RESPONSES BASED ON TISSUE ENERGY DEMAND}

Neuronal activity is tightly coupled to increased local blood flow by neurovascular coupling in a response termed functional hyperemia. Neurovascular coupling is a complex, multi-modal response involving numerous identified signaling pathways and resulting in vasodilation of penetrating arterioles upstream of regions with enhanced of activity, and vasoconstriction in regions with abundant substrate supply and lower activity (Devor et al., 2007). The net effect of this response is to enhance glucose and oxygen delivery from blood to meet neuronal and glial energy demands.

Astrocytic spatial architecture permits relay of signals from synapses to penetrating arterioles and capillaries. As part of the multi-faceted response of astrocytes to increased neuronal activity, synaptic neurotransmission triggers elevated intracellular astrocyte $\mathrm{Ca}^{2+}$ through diverse receptor types including $\mathrm{GABA}_{B}$ receptors (Kang et al., 1998; Bettler et al., 2004; Meier et al., 2008), acetylcholine muscarinic receptors (Takata et al., 2011; Navarrete et al., 2012), $\alpha$-adrenergic receptors (Duffy and Macvicar, 1995; Bekar et al., 2008), H1 histamine receptors (Shelton and McCarthy, 2000), endocannabinoid receptors (Navarrete and Araque, 2008, 2010), GGluR $_{5}$ (Zonta et al., 2003), and P2Y receptors (Simard et al., 2003). Astrocyte cytosolic $\mathrm{Ca}^{2+}$ elevations (Simard et al., 2003; Zonta et al., 2003; Filosa et al., 2004; Schummers et al., 2008), and inositol-3-phosphate signaling (Straub et al., 2006) are central to neurovascular coupling, stimulating release of vasoactive compounds that dilate or constrict neighboring arterioles (Zonta et al., 2003; Mulligan and Macvicar, 2004; Metea and Newman, 2006; Takano et al., 2006; Gordon et al., 2008). The polarity (i.e., constriction vs. dilation) of these vascular responses involves multiple pathways, discussed in later sections.

\section{ARACHIDONIC ACID METABOLITES}

Elevated astrocyte cytosolic $\mathrm{Ca}^{2+}$ stimulates activity of phospholipase $\mathrm{A}_{2}\left(\mathrm{PLA}_{2}\right)$, which hydrolyzes phospholipids to produce arachidonic acid (AA) (Mulligan and Macvicar, 2004; Sun et al., 2005). AA metabolism by several enzymes produces different molecules with variable vascular effects (Figure 3). In brain slices and in vivo, a non-selective cyclooxygenase (COX) or COX-1 inhibitor blocked arteriolar vasodilation after astrocyte $\mathrm{Ca}^{2+}$ stimulations, suggesting AA is metabolized by astrocyte COX-1 to prostaglandin $\mathrm{E}_{2}\left(\mathrm{PGE}_{2}\right)$ (Zonta et al., 2003; Takano et al., 2006; Gordon et al., 2008). In cortical astrocytes and retinal glia, AA is also metabolized by cytochrome P450 epoxygenase to vasodilator, epoxyeicosatrienoic acids (EETs) (Peng et al., 2002; Metea and Newman, 2006; Liu et al., 2011). Both $\mathrm{PGE}_{2}$

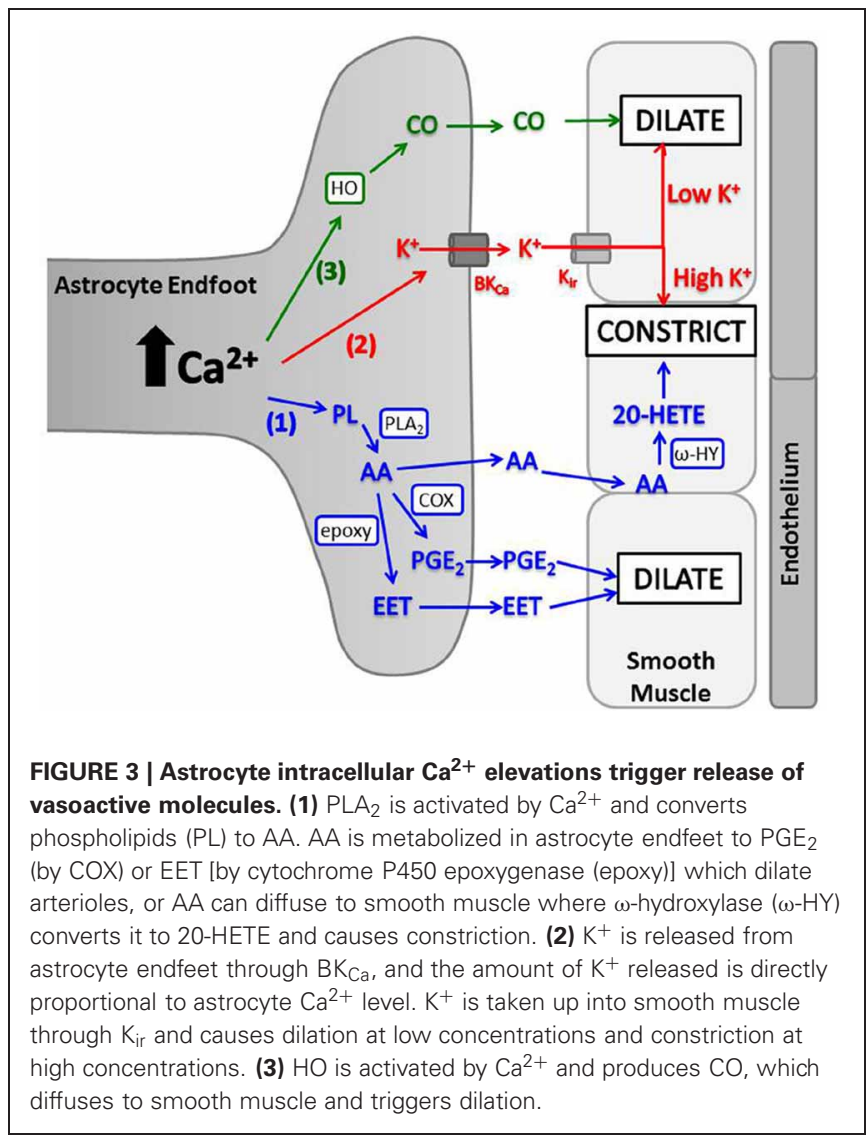

and EETs open smooth muscle large conductance $\mathrm{Ca}^{2+}$-sensitive $\mathrm{K}^{+}\left(\mathrm{BK}_{\mathrm{Ca}}\right)$ channels, triggering hyperpolarization and decreased voltage-gated calcium channel (VGCC) activity (Gebremedhin et al., 1992; Miura and Gutterman, 1998; Higashimori et al., 2010). EETs also indirectly stimulate $\mathrm{BK}_{\mathrm{Ca}}$ channels by increasing $\mathrm{Ca}^{2+}$ sparks (Earley et al., 2005). AA metabolism can also cause vasoconstriction. AA can diffuse to smooth muscle cells and be rapidly metabolized by $\omega$-hydroxylase (another cytochrome P450 enzyme) to produce 20-hydroxyeicosatetraenoic acid (20-HETE) (Mulligan and Macvicar, 2004; Metea and Newman, 2006). 20HETE causes smooth muscle contraction by inhibiting vascular $\mathrm{BK}_{\mathrm{Ca}} \mathrm{K}^{+}$channels, leading to depolarization and increased $\mathrm{Ca}^{2+}$ entry through VGCC.

At first, these opposing effects of astrocyte AA metabolism on vascular lumen diameter represented a confusing dichotomy in the field. However, the last 5 years have brought some mechanistic clarity showing that the directional control of AA metabolism is finely controlled by metabolic need and nitric oxide (NO). In brain slices and retinal preparations equilibrated with 95$100 \%$ oxygen, elevated astrocyte $\mathrm{Ca}^{2+}$ led to vasoconstriction mediated by 20-HETE production (Mulligan and Macvicar, 2004; Gordon et al., 2008; Mishra et al., 2011). However, in brain slices and retinal preparations treated with $20 \%$ oxygen, astrocyte $\mathrm{Ca}^{2+}$ elevations caused vasodilation induced by $\mathrm{PGE}_{2}$ produced from COX-1 activity (Gordon et al., 2008; Mishra et al., 2011). Vasodilation induced by direct astrocyte $\mathrm{Ca}^{2+}$ stimulation in vivo was also mediated by COX-1 (Takano et al., 2006). 
Interestingly, part of the mechanism for dictating response directionality appears to be related to lactate production by astrocytes, revealing another critical role for lactate alongside the ANLSH. At $20 \%$ oxygen, astrocytes oxidize glucose and produce lactate (Gordon et al., 2008). Astrocyte endfeet express a prostaglandin-lactate transporter that exchanges intracellular lactate for extracellular $\mathrm{PGE}_{2}$ (Chan et al., 2002). Thus, at 20\% oxygen, increased extracellular lactate from astrocyte glycolysis inhibits the prostaglandin-lactate transporter, resulting in elevated extracellular $\mathrm{PGE}_{2}$ and vasodilation (Gordon et al., 2008). Current consensus suggests astrocytes maintain vascular tone equilibrium (between vasodilation and vasoconstriction) under physiological conditions. When synaptic activity is minimal and oxygen consumption is low, vasoconstriction by 20-HETE is favored because $\mathrm{PGE}_{2}$ is taken up rapidly through prostaglandinlactate transporters. During periods of elevated activity, oxygen is depleted and lactate is released from astrocytes, leading to inhibition of the prostaglandin-lactate transporter, more extracellular $\mathrm{PGE}_{2}$, and vasodilation. This mechanism couples cerebral blood flow regulation and the ANLSH, since astrocyte lactate production may act as a neuronal energy source and signaling molecule to increase blood flow.

While astrocytes may "sense" the oxygen content in their local environment by producing variable lactate levels in vitro (Gordon et al., 2008), the relevance of this mechanism in vivo is not clear. In vivo, oxygen levels may not influence neurovascular coupling like they do in vitro preparations (Lindauer et al., 2010; Mishra et al., 2011). In ex vivo retinal preparations, for example, while incubation with $100 \%$ oxygen increases tissue partial pressure of oxygen $\left(\mathrm{pO}_{2}\right)$ 16-fold, administering $100 \%$ oxygen to anesthetized rats only modestly elevates retinal $\mathrm{pO}_{2}$ (Mishra et al., 2011). Consequently, retinal neurovascular coupling favors vasodilation under normoxic and hyperoxic conditions in vivo, in contrast to vasoconstriction in vitro under high $\mathrm{pO}_{2}$. In addition, physiologic cerebral oxygen levels are between 12 and $38 \mathrm{mmHg}$ (Jamieson and Vandenbrenk, 1963; Metzger et al., 1971; O'Hara et al., 2005), suggesting 20-HETE synthesis, which is dependent on binding of molecular oxygen as a cofactor and has a $\mathrm{K}_{\mathrm{m}} \mathrm{O}_{2}$ (Michaelis constant for oxygen) of $60-70 \mathrm{mmHg}$ (Harder et al., 1996), is low in normoxia. Conversely, production of dilatory prostaglandins and EETs, both with $\mathrm{K}_{\mathrm{m}} \mathrm{O}_{2} \leq 10 \mathrm{mmHg}$ (Harder et al., 1996; Juranek et al., 1999), would be favored at physiologic oxygen. This suggests that the effect of oxygen on the kinetics of AA metabolism may be sufficient to dictate vascular response polarity as observed in vitro; however, the influence of oxygen on responses in vivo may favor dilation and requires further investigation.

The role of NO in functional hyperemia further complicates neurovascular signaling, as $\mathrm{NO}$ also modulates AA metabolism (Metea and Newman, 2006). Traditionally, NO has been considered a direct vasodilator, stimulating vascular smooth muscle guanylyl cyclase leading to activation of $\mathrm{K}^{+}$channels and hyperpolarization (Ignarro et al., 1999). However, NO can also inhibit cytochrome $\mathrm{P} 450$ enzymes, such as $\omega$-hydroxylase, thereby reducing 20-HETE production (Alonso-Galicia et al., 1998, 1999), or cytochrome P450 epoxygenase, mitigating EET production (Udosen et al., 2003). Additionally, NO weakly activates COX-1, while suppressing COX-2 (Fujimoto et al., 2004), which may affect prostaglandin levels. Overall, cerebral vasodilation by $\mathrm{NO}$ likely involves both smooth muscle effects and inhibition of 20-HETE production, thereby favoring lumen expansion by prostaglandins and EETs (Sun et al., 2005; Attwell et al., 2010). The opposite effect of NO on AA metabolism, that is inhibition of dilatory metabolism in deference to 20-HETE, may also occur at elevated tissue oxygen in vitro. In retinal preparations maintained in $95 \% \mathrm{O}_{2}$, NO-enhanced constriction produced by glial activation in a manner thought to result from inhibition of EET formation (Metea and Newman, 2006). There is evidence that all NOS isoforms (i.e., nNOS, eNOS, or iNOS) could be involved in 20-HETE modulation. Reduction of vasodilation in vivo by an nNOS inhibitor was reversed by 20-HETE inhibition, suggesting neuronal NO inhibits 20-HETE production in live animals (Liu et al., 2008). Recent evidence from brain slices also indicates that eNOS permits dilation through suppression of 20-HETE synthesis (Stobart et al., 2013). iNOS is more likely to be involved in neurovascular coupling during pathological conditions. Inhibition of iNOS, which is elevated in retinal glia of diabetic animal models, rescued functional hyperemia, possibly by attenuating EET production (Mishra and Newman, 2010).

\section{POTASSIUM}

Extracellular $\mathrm{K}^{+}$is generated by working neurons and is an effective vasodilator, giving it suitable properties as a neurovascular coupling mediator. Astrocytes have long been known to regulate neuronal membrane potential by removing synaptic $\mathrm{K}^{+}$ (Amedee et al., 1997; Kofuji and Newman, 2004), and astrocytes express inwardly rectifying $\mathrm{K}_{\mathrm{ir}} 4.1 \mathrm{~K}^{+}$channels (Sontheimer and Waxman, 1993; Sontheimer, 1994) and large conductance $\mathrm{Ca}^{2+}$. sensitive $\mathrm{K}^{+}$channels $\left(\mathrm{BK}_{\mathrm{Ca}}\right)$ on vascular endfeet (Price et al., 2002) as a potential egress route for vasodilatory $\mathrm{K}^{+}$. In retinal preparations, it was suggested vasodilation can be triggered via $\mathrm{K}^{+}$efflux through glial endfoot $\mathrm{K}_{\mathrm{ir}} 4.1$ channels in response to neurotransmission (Newman et al., 1984; Paulson and Newman, 1987), but studies of $\mathrm{K}_{\mathrm{ir}} 4.1$ knockout mice failed to support this idea (Metea et al., 2007). A second mechanism was proposed involving $\mathrm{Ca}^{2+}$-dependent astrocyte $\mathrm{BK}_{\mathrm{Ca}}$ channels (Filosa et al., 2006). The idea is that astrocytic $\mathrm{Ca}^{2+}$ increases lead to $\mathrm{BK}_{\mathrm{Ca}}$ channel activation, $\mathrm{K}^{+}$release, and smooth muscle relaxation. Moderate astrocytic $\mathrm{Ca}^{2+}$ increases indeed triggered $\mathrm{BK}_{\mathrm{Ca}}$ channel-induced dilation of neighboring arterioles, but larger astrocyte $\mathrm{Ca}^{2+}$ signals produced greater $\mathrm{BK}_{\mathrm{Ca}}$ channel opening, higher astrocyte $\mathrm{K}^{+}$release and vasoconstriction (Figure 3) (Girouard et al., 2010). This polarity was dictated by a threshold extracellular $\mathrm{K}^{+}\left(\left[\mathrm{K}^{+}\right]_{\mathrm{o}}\right)$ concentration of $20 \mathrm{mM}$. Lower than this threshold, conductance of smooth muscle inward rectifying $\mathrm{K}_{\mathrm{ir}} 2.1 \mathrm{~K}^{+}$channels (Bradley et al., 1999) was enhanced, causing hyperpolarization, reduced VGCC activity, and vascular smooth muscle relaxation (Girouard et al., 2010). In contrast, $\left[\mathrm{K}^{+}\right]_{\mathrm{o}}$ larger than $20 \mathrm{mM}$ caused smooth muscle depolarization, increasing VGCC conductance, and vasoconstriction (Knot et al., 1996; Knot and Nelson, 1998). This represents another potential mechanism of activity-dependent vasodilation mediated by astrocytes. Moreover, it is another mechanism by which astrocytes 
could theoretically select for dilation or constriction based on magnitude of $\mathrm{K}^{+}$release (Dunn and Nelson, 2010).

AA metabolite and $\mathrm{K}^{+}$signaling occur in parallel to regulate cerebral blood flow (Filosa et al., 2006) and may interact since AA metabolites also affect smooth muscle ion conductance. In renal arteries, $\mathrm{PGE}_{2}$ can induce smooth muscle $\mathrm{BK}_{\mathrm{Ca}}$ channel- mediated dilation through EP2 or EP4 prostanoid receptors (Zhang et al., 2005), but this mechanism has not been tested in cerebral arteries. Also, astrocyte $\mathrm{BK}_{\mathrm{Ca}}$ channel activity is increased by EETs (Higashimori et al., 2010), suggesting AA metabolites can modulate $\mathrm{K}^{+}$release into the perivascular space, but the vascular implications of this interaction have not been studied.

\section{CARBON MONOXIDE}

Carbon monoxide (CO) is produced by heme oxygenase (HO) and can have vasoactive effects. On a cellular level, $\mathrm{CO}$ can relax vascular smooth muscle by increasing coupling between smooth muscle $\mathrm{BK}_{\mathrm{Ca}}$ channels and local $\mathrm{Ca}^{2+}$ transients, similar to EET activity (Figure 3; Jaggar et al., 2002; Wu et al., 2002; Xi et al., 2010). CO-mediated vasorelaxation has been observed in peripheral tissues such as liver (Suematsu et al., 1994, 1995) and carotid arteries (Brian et al., 1994), but cerebrovascular results are varied (Brian et al., 1994; Leffler et al., 1999; Ishikawa et al., 2005; Leffler et al., 2006a; Li et al., 2008; Xi et al., 2010, 2011; Morikawa et al., 2012). Brain arteries from rabbits and dogs demonstrated no response to CO (Brian et al., 1994), while arteries from rats and piglets dilated in response to CO (Leffler et al., 1999; Jaggar et al., 2002; Holt et al., 2007; Li et al., 2008; Xi et al., 2010, 2011) or constricted based on CO-induced inhibition of $\mathrm{NO}$ dilation pathways (Ishikawa et al., 2005). In piglet studies, glutamateinduced vasodilation was mediated by $\mathrm{CO}$, as $\mathrm{HO}$ inhibitors blocked lumen diameter increases in isolated arteries (Fiumana et al., 2003) and pial arteries in vivo (Leffler et al., 1999; Robinson et al., 2002). Glutamate stimulates endothelium-dependent dilation through CO production from endothelial and smooth muscle cells (Fiumana et al., 2003; Leffler et al., 2003), but also induces CO production in astrocyte endfeet (Leffler et al., 2006b; Parfenova et al., 2012) by $\mathrm{Ca}^{2+}$ and calmodulin-dependent activation of $\mathrm{HO}$ (Xi et al., 2011). This astrocyte-specific response can reportedly mediate vasodilation in vivo (Li et al., 2008) indicating $\mathrm{CO}$ is another diffusible, vasoactive molecule, released upon astrocytic activation by neurotransmission. Astrocyte CO production and dilation of piglet pial arteries in vivo can be enhanced by adenosine diphosphate (Kanu and Leffler, 2009), NO (Barkoudah et al., 2004; Leffler et al., 2005a,b), AA and PGE 2 (Kanu et al., 2006; Kanu and Leffler, 2011), suggesting an interaction between other dilatory mechanisms and $\mathrm{HO}$ activity. A study of adult rat pial arteries in vivo indicated $\mathrm{CO}$-induced cerebral vasoconstriction by inhibiting $\mathrm{NO}$ production (Ishikawa et al., 2005), and similar results were observed in piglets, but after prolonged exposure to CO (Knecht et al., 2010; Leffler et al., 2011). Therefore, there may be a polarity to CO-mediated cerebrovascular effects, akin to similar effects seen with AA metabolism and $\mathrm{K}^{+}$effects.

In summary, astrocytes are not only important for regulating synaptic environments and the supply of energy metabolites to neurons, but they are also central to the regulation of neurovascular coupling by releasing several molecules, including AA metabolites, $\mathrm{K}^{+}$, and $\mathrm{CO}$, in response to synaptic transmission. We are only just beginning to understand how these pathways work in concert to fine-tune regulation of cerebral blood flow.

\section{ASTROCYTE CONTROL OF CEREBRAL BIOENERGETICS CAN CONTRIBUTE TO DISEASE}

Multiple brain diseases and injuries are associated with aberrant energy metabolism, dysfunctional glutamate cycling by astrocytes, and altered neurovascular coupling. Here, we discuss the major bioenergetic changes and astrocyte dysfunction in Alzheimer's disease (AD), cerebral ischemia, and epilepsy.

\section{ALZHEIMER'S DISEASE}

$\mathrm{AD}$ is the most common form of dementia, characterized by declining cognitive performance and memory (McKhann et al., 1984). AD pathology is characterized by two types of lesionsamyloid- $\beta$ (A $\beta)$ plaques, consisting of insoluble, extracellular deposits of $A \beta$ peptide fibrils, and neurofibrillary tangles, composed of intracellular neuronal deposits of hyperphosphorylated and crosslinked tau protein (Merz et al., 1983; Braak and Braak, 1988). A $\beta$ peptides are linked to synaptic dysfunction, activation of microglia and astrocytes, and oxidative stress, but the precise contribution of plaque formation to disease pathogenesis remains controversial (Fuller et al., 2009).

During $\mathrm{AD}$, astrocytes undergo morphological changes, related to proximity of $A \beta$ deposits. In dementia patients and transgenic mice, extensive reactive gliosis appears near $\mathrm{A} \beta$ plaques (Rodriguez et al., 2009; Simpson et al., 2010), while astrocytes farther away display dystrophic changes such as decreased complexity, surface area, and volume of cell processes (Senitz et al., 1995; Rodriguez et al., 2009). In many cases, abnormal glial morphology occurs early in disease on-set before amyloid deposition is apparent (Scheff et al., 2007; Rodriguez et al., 2009). Astrocyte dystrophy and reactive astrogliosis may greatly impair astrocytic modulation of synaptic environments and neuronal metabolism, exacerbating $\mathrm{AD}$ progression (Fuller et al., 2009; Steele and Robinson, 2012). For example, brain glucose metabolism is diminished in pre-clinical patients (Mosconi et al., 2008) and cerebral glucose uptake in transgenic AD mice (Merlini et al., 2011) and $\mathrm{AD}$ patients (Alexander et al., 2002) is significantly reduced, often before $A \beta$ plaques or neurofibrillary tangles are detected (Small et al., 2000). Glycogen-derived lactate is important for memory formation in healthy brain (Gibbs et al., 2006; Newman et al., 2011; Suzuki et al., 2011), and dysfunction of this pathway could contribute to $\mathrm{AD}$ pathogenesis. Transgenic $\mathrm{AD}$ mice demonstrate decreased brain lactate release during neuronal stimulation (Merlini et al., 2011). In day-old chicks treated with A $\beta 1-42$ peptide, memory consolidation was rescued upon injection of energy substrates, such as acetate, a substrate oxidized specifically by astrocytes (Gibbs et al., 2009). This suggests A $\beta$ may damage astrocyte glycolysis and lactate production, reducing brain metabolism, and impairing memory.

The astrocyte glutamate-glutamine shuttle is also altered during AD. Expression of astrocyte glutamate transporter, EAAT2, is reduced in both transgenic mice and dementia patients, 
suggesting astrocytes take up less synaptic glutamate (Li et al., 1997; Masliah et al., 2000; Simpson et al., 2010). Also, both glutamine synthetase activity (Smith et al., 1991) and the concentration of glutamine in cerebrospinal fluid is reduced in AD patients (Csernansky et al., 1996; Jimenez-Jimenez et al., 1998). The confluence of these events results in a dysregulation of glutamate homeostasis and reduced transfer of glutamine to neurons from astrocytes. Neurons in AD brains aberrantly express astrocyte proteins, including the amino acid transporter, EAAT1 (Scott et al., 2002), and glutamine synthetase (Robinson, 2000), possibly in an attempt to normalize glutamate handling and limit excitotoxicity. Neuronal expression of EAAT1 is correlated with neurofibrillary tangle formation (Scott et al., 2002), while glutamine synthetase expression corresponds with plaque formation (Robinson, 2000). Since these enzymes and transporters are critical for glutamate uptake and the glutamate-glutamine shuttle, such dramatic changes in cellular distribution suggest profound astrocyte dysfunction and impaired glutamate handling during $\mathrm{AD}$. In combination with reduced energy metabolism, this may greatly affect neuronal viability and synaptic transmission (Rodriguez et al., 2009).

Impaired vascular reactivity, reduced neurovascular coupling, and diminished resting blood flow are all associated with AD (Mentis et al., 1996; Warkentin and Passant, 1997; Niwa et al., 2000, 2001; Iadecola, 2004), and could be attributed to astrocytes and hemodynamic dysfunction. Cultured astrocytes treated with $A \beta$ peptides (1-42 and 25-35) (Abramov et al., 2003; Chow et al., 2010) and in vivo astrocytes from transgenic $\mathrm{AD}$ mice exhibit increased frequency of spontaneous, focal intracellular $\mathrm{Ca}^{2+}$ responses not coupled with neuronal activity (Takano et al., 2007; Kuchibhotla et al., 2009). Intercellular $\mathrm{Ca}^{2+}$ waves between astrocytes were also increased in frequency and amplitude in both cultured cells and in vivo (Haughey and Mattson, 2003; Kuchibhotla et al., 2009). Furthermore, A $\beta 40$-peptide accumulates in blood vessel walls (Selkoe and Schenk, 2003; Agyare et al., 2012) causing endothelial cell deformity, smooth muscle deterioration (Farkas and Luiten, 2001; Merlini et al., 2011), and pericyte toxicity (Wilhelmus et al., 2007). This is linked to reduced free NO and vasoconstriction (Thomas et al., 1996; Niwa et al., 2001), and suggests that $A \beta$ accumulation may alter the functional neurovascular unit. The concentration of reactive oxygen species (ROS) also increases in AD transgenic mice (Park et al., 2004), which are known to reduce production of vaso-active molecules, as observed in vitro (Fleming, 2004; Sun et al., 2008). Thus, dysfunctional neurovascular coupling during $\mathrm{AD}$ could be caused by altered astrocyte $\mathrm{Ca}^{2+}$ signaling, increased ROS, and gross vascular abnormalities, which change normal intrinsic vascular tone. Astrocyte dysfunction appears to be central to AD initiation and progression, and these cells have now become future therapeutic targets (Fuller et al., 2009).

\section{CEREBRAL ISCHEMIA}

During cerebral ischemia, blood flow is restricted by cortical or subcortical occlusion, chronically impaired vascular reactivity or cardiac arrest. Bioenergetic failure results (Hertz, 2008) in a cytotoxic cascade characterized by lactate and proton acidification (Silver et al., 1997) and ROS generation, (Abramov et al.,
2007), inhibition of $\mathrm{Na}^{+} / \mathrm{K}^{+}$ATPases, membrane depolarization (Silver et al., 1997) and elevation of extracellular glutamate due to depolarization-induced vesicular release and non-vesicular egress mechanisms. This initiates further membrane depolarization, mitochondrial damage, excitotoxicity, and neuronal death (Schild et al., 2003; Brookes et al., 2004; Nicholls, 2004; Nicholls et al., 2007). Neurons are very sensitive to this chain reaction, while astrocytes are more resistant because they can increase their glycolytic rate (Walz and Mukerji, 1990) or utilize alternate energy substrates for ATP production (Edmond et al., 1987; Hertz, 2003; Hertz and Hertz, 2003). Astrocytes also exploit glutathione stores to limit ROS damage (Juurlink, 1997). In early ischemic stages, astrocytes may help ailing neurons, but prolonged ischemic stress damages astrocytes, which may contribute to neuronal demise (Rossi et al., 2007). As described below, astrocytes affect neuronal survival and metabolism during ischemia through glutamate handling, lactate shuttling, and glycogen breakdown, and the transport of metabolites through gap junctions.

During ischemia, neuronal ionic gradients are disrupted by $\mathrm{Na}^{+} / \mathrm{K}^{+}$ATPase inhibition, elevating extracellular glutamate concentrations (Bosley et al., 1983; Goldberg et al., 1988; Hillered et al., 1989). In early stages, astrocytes take up and accumulate intracellular glutamate (Hertz et al., 1998; Voloboueva et al., 2007) in an attempt to balance the extracellular environment, but they continue to shuttle glutamine to neurons, facilitating additional glutamate release (Haberg et al., 2001). Prolonged ischemia disrupts the glutamate-glutamine cycle (Gorovits et al., 1997) due to depleted ATP levels, accumulation of intracellular $\mathrm{Na}^{+}$and reversal of GLT1 and GLAST to cause facilitated extrusion of glutamate (Anderson and Swanson, 2000; Phillis et al., 2000; Bonde et al., 2003). Furthermore, astrocytes swell and release yet more glutamate through volume-regulated anion channels (Kimelberg et al., 1990). These observations have generated interest in astrocyte glutamate handling as a potential ischemic therapeutic target, since upregulated expression or activity of glutamate transporters or inhibition of volume-regulated anion channels may decrease glutamate excitotoxicity (Rossi et al., 2007).

Progression of neuronal death during ischemia is dependent on availability of energy substrates. Experimental inhibition of lactate transporters (MCTs) during ischemia exacerbates neuronal death and astrocytes display increased conversion of glycogen to lactate (via glucose-6-phosphate) during this time (Brown et al., 2005; Tekkok et al., 2005; Suh et al., 2007), suggesting lactate and glycogen are important for maintaining ATP levels and neuronal survival. Lactate can also diffuse through astrocyte gap junctions (Rouach et al., 2008), which remain open during ischemia (Cotrina et al., 1998), facilitating the beneficial flux of lactate within the astrocytic network. As oxygen is depleted, astrocytes appear to be able to sustain neuronal function via anaerobic glycolysis (Rossi et al., 2007). However, there is a fine balance between benefit and injury and eventually lactate builds to concentrations which induce acidosis and cellular damage (Li and Siesjo, 1997). Further experimental testing is required to determine the role of astrocyte glycogen during ischemia. Brain regions with higher than normal glycogen concentrations are more resistant to ischemic damage (Swanson et al., 1989), and increasing glycogen stores in cultured astrocytes reduces neuronal death 
during glucose deprivation (Swanson and Choi, 1993). Protective effects in vivo may also be enhanced by increasing glycogen stores, either through inhibition of GlyP (Suh et al., 2007) or by elevating glycogen synthase activity (Rossi et al., 2007). In cell culture models of ischemia, propagation of signals and metabolites through the glial network is increased through hemichannels (Contreras et al., 2002). This may exacerbate tissue damage as increased hemichannel activity allows $\mathrm{Na}^{+}$and $\mathrm{Ca}^{2+}$ to diffuse into astrocytes, while glutamate flows out, furthering excitotoxicity (Ye et al., 2003). Also, in astrocyte cultures, glutathione (an important astrocytic antioxidant) is lost over time through hemichannels, limiting ROS protection (Rana and Dringen, 2007). While both hemichannels and gap junctions respond to ischemic signals, they are difficult in vivo therapeutic targets as both are inhibited by the same antagonists, obscuring potential benefits (Rossi et al., 2007).

Reperfusion after ischemia is characterized by reduced blood flow (Leffler et al., 1989) due to disruption of the neurovascular unit via neuronal and vascular ischemic damage (Del Zoppo, 2010). Reduced neurovascular coupling exacerbates ischemic injury, which may increase infarct size. Blood flow is partly reduced because fibrin, activated platelets and/or leukocytes occlude capillaries and venules (Del Zoppo and Mabuchi, 2003). Evidence also suggests that AA metabolite (EETs and 20HETE) signaling is altered during ischemia, which contributes to decreased blood flow and neurovascular coupling. Recent therapeutic studies have elevated EET levels using inhibitors of soluble epoxide hydrolase (sEH), an enzyme that degrades EETs (Imig and Hammock, 2009). sEH inhibitors are beneficial regardless of administration time, since infarct size is decreased in rodents when the drug is given chronically, shortly after the ischemic insult or during reperfusion (Dorrance et al., 2005; Zhang et al., 2007, 2008; Simpkins et al., 2009). EETs mediate this protection, as inhibition of CYP epoxygenase (the EET synthesis enzyme) prevents sEH benefits (Zhang et al., 2007, 2008). This protective mechanism increases astrocyte survival (Liu and Alkayed, 2005), elevates antiapoptotic factors (Simpkins et al., 2009) and increases neurovascular coupling (Zhang et al., 2007, 2008). Conversely, 20-HETE is elevated during ischemia (Tanaka et al., 2007), and inhibition of 20-HETE production is also neuroprotective in rodent models (Miyata et al., 2005; Poloyac et al., 2006; Tanaka et al., 2007; Dunn et al., 2008; Renic et al., 2009). Reduction of 20-HETE inhibits ROS production (Dunn et al., 2008), limits vasoconstriction and increases blood flow during reperfusion (Miyata et al., 2005; Dunn et al., 2008). Taken together, evidence suggests AA metabolite signaling is dysfunctional during and after cerebral ischemia, whereby EETs are decreased and 20-HETE is elevated. By inhibiting EET degradation and 20-HETE production, functional hyperemia can be restored, and these pathways make promising therapeutic targets.

Focal cerebral ischemia causes altered glutamate handling and lack of energy substrates, which triggers neuronal excitotoxicity, ATP depletion, and ROS production (Hertz, 2008). In early stages of ischemia, astrocytes are less susceptible to damage and may help protect neurons through glutamate uptake, glycogen hydrolysis to lactate for energy, and conduction of protective molecules through gap junctions. However, prolonged ischemia damages the neurovascular unit reducing blood flow and functional hyperemia during reperfusion. Current therapeutic targets are meant to promote astrocyte protection of neurons and help restore proper circulation after stroke.

\section{EPILEPSY}

Epilepsy is characterized by sudden, temporary synchronization of electrical charges in groups of neurons, which may manifest as seizures. The origins of this disorder are not completely understood (McCormick and Contreras, 2001; Scharfman, 2007), but neuronal hyperexcitability is believed to be caused by disequilibrium between glutamatergic and GABAergic neurotransmission, either by decreased inhibitory (GABA) circuits or excessive glutamatergic release (Dudek et al., 1999; Uhlhaas and Singer, 2006). Dysfunctional astrocyte glutamate-glutamine cycling is also involved (Tian et al., 2005), as astrocyte expression of EAAT2 is diminished in epilepsy patients (Proper et al., 2002; Fotheringham et al., 2007), and knock-down of glutamate transporters [EAAC1 (Sepkuty et al., 2002), GLT-1 (Tanaka et al., 1997), and GLAST (Watase et al., 1998)] in animal models exacerbates neuronal excitability. Also, glutamine synthetase expression is reduced by $40 \%$ in astrocytes of epilepsy patients, suggesting that glutamate degradation is greatly diminished (Eid et al., 2004). Therefore, dysfunctional glutamate metabolism in astrocytes could contribute to neuronal synchronization and hyperexcitability.

Ion homeostasis by astrocytes is altered during epilepsy. Particularly, both $\mathrm{K}_{\mathrm{ir}}$ currents and aquaporin 4 expression are reduced, (D'Ambrosio, 2004; Eid et al., 2005) and this results in elevated extracellular $\mathrm{K}^{+}$, decreased water homeostasis, and reduced seizure thresholds (Binder and Steinhauser, 2006). Astrocytes also display elevated intracellular $\mathrm{Ca}^{2+}$ signals before and during seizure activity in rodents (Tian et al., 2005; GomezGonzalo et al., 2010, 2011), which are mediated by mGluR and purinergic receptors, and may further exacerbate neuronal activation by triggering gliotransmission (Gomez-Gonzalo et al., 2010). Interestingly, common antiepileptic drugs, such as valproate and phenytoin, reduce astrocytic $\mathrm{Ca}^{2+}$ increases (Tian et al., 2005).

Cerebral bioenergetics are aberrantly regulated in epilepsy, but the precise changes remain unknown. Epilepsy patients display high levels of glucose uptake and hypermetabolism during seizures (Engel et al., 1983), and low levels of glucose uptake and hypometabolism between seizures (Engel et al., 1982). In animal models of epilepsy, astrocyte glycogen accumulates before the onset of seizures for possible conversion to neuronal energy substrates (Bernard-Helary et al., 2000). Glycolytic inhibitors, such as 2-deoxy-D-glucose, have antiepileptic properties (Garriga-Canut et al., 2006), suggesting glycolysis is necessary for neuronal hyperexcitability and synchronization. Also, glucose flux from blood vessels to neurons through astrocytic gap junctions can partially sustain epileptiform activity in brain slices (Rouach et al., 2008). However, connexin knockout mice experience spontaneous interictal bursts and neuronal hyperexcitability, which has been attributed to decreased buffering of extracellular $\mathrm{K}^{+}$and glutamate (Wallraff et al., 2006; Cloix and Hevor, 2009; Pannasch et al., 2011; Bedner and Steinhauser, 2013). Gap junction trafficking is reportedly altered in epilepsy, possibly permitting elevated 
extracellular $\mathrm{K}^{+}$and glutamate, but how this effects the flow of energy substrates remains unclear (Bedner and Steinhauser, 2013).

Epileptiform activity triggers increased blood flow and deoxygenates hemoglobin (Suh et al., 2006) to meet energy and oxygen demand of active neurons (Kuhl et al., 1980). However, hyperemia may not fully support neurons, since some studies suggest chronic epilepsy may cause ischemic-like tissue damage (Suh et al., 2006). A lag time was identified between astrocyte endfeet $\mathrm{Ca}^{2+}$ elevations and vasodilation of pre-constricted arterioles during synchronous bursts in rat brain slices treated with 95\% oxygen, indicating astrocyte-independent neurovascular coupling mechanisms may be more prevalent in epilepsy (Gomez-Gonzalo et al., 2011). However, the cellular pathways influencing the hemodynamic response during epilepsy have not been investigated (Kovacs et al., 2012).

Astrocytes may play an important role in epilepsy, but it is unclear if they promote neuronal excitability, or merely sustain seizures and epileptogenesis. Several astrocyte functions are altered during epilepsy including glutamate-glutamine shuttle, ion homeostasis, and movement of metabolites, but the role of astrocytes in functional hyperemia during seizure activity is unknown. In the future, astrocyte glutamate uptake, blood flow control, or metabolism could be targeted to limit neuron excitability.

\section{REFERENCES}

Abramov, A. Y., Canevari, L., and Duchen, M. R. (2003). Changes in intracellular calcium and glutathione in astrocytes as the primary mechanism of amyloid neurotoxicity. J. Neurosci. 23, 5088-5095.

Abramov, A. Y., Scorziello, A., and Duchen, M. R. (2007). Three distinct mechanisms generate oxygen free radicals in neurons and contribute to cell death during anoxia and reoxygenation. J. Neurosci. 27, 1129-1138.

Agulhon, C., Fiacco, T. A., and McCarthy, K. D. (2010). Hippocampal short- and longterm plasticity are not modulated by astrocyte $\mathrm{Ca} 2+$ signaling. Science 327, 1250-1254.

Agyare, E., Leonard, S., Curran, G., Yu, C., Lowe, V., Paravastu, A. K., et al. (2012). Traffic jam at the blood brain barrier promotes greater accumulation of Alzheimer's disease amyloid-beta proteins in the cerebral vasculature. Mol. Pharm. doi: 10.1021/mp300352c. [Epub ahead of print].

Alexander, G. E., Chen, K., Pietrini, P., Rapoport, S. I., and Reiman, E. M. (2002). Longitudinal PET evaluation of cerebral metabolic decline in dementia: a potential outcome measure in Alzheimer's disease treatment studies. Am. J. Psychiatry 159, 738-745.
Alkire, M. T., Haier, R. J., Barker, S. J., Shah, N. K., Wu, J. C., and Kao, Y. J. (1995). Cerebral metabolism during propofol anesthesia in humans studied with positron emission tomography. Anesthesiology 82, 393-403. discussion: 327A.

Alkire, M. T., Haier, R. J., Shah, N. K., and Anderson, C. T. (1997). Positron emission tomography study of regional cerebral metabolism in humans during isoflurane anesthesia. Anesthesiology 86, 549-557.

Alkire, M. T., Pomfrett, C. J., Haier, R. J., Gianzero, M. V., Chan, C. M., Jacobsen, B. P., et al. (1999). Functional brain imaging during anesthesia in humans: effects of halothane on global and regional cerebral glucose metabolism. Anesthesiology 90, 701-709.

Allaman, I., Pellerin, L., and Magistretti, P. J. (2000). Protein targeting to glycogen mRNA expression is stimulated by noradrenaline in mouse cortical astrocytes. Glia 30, 382-391.

Alonso-Galicia, M., Hudetz, A. G., Shen, H., Harder, D. R., and Roman, R. J. (1999). Contribution of 20-HETE to vasodilator actions of nitric oxide in the cerebral microcirculation. Stroke 30, 2727-2734. discussion: 2734.

Alonso-Galicia, M., Sun, C. W., Falck, J. R., Harder, D. R., and Roman,

\section{CONCLUSION}

Astrocytes were once considered the "glue" of the brain with little importance to brain function; however, they have emerged as modulators of brain bioenergetics, blood flow, and neuronal survival. Based on spatial orientation, gap junction connections, and complexity, astrocytes are well-situated to influence synaptic environments and function as "gatekeepers" of neuronal metabolism and blood flow. This involves complex, multi-modal mechanism where astrocytes "listen" to synaptic activity and respond through (a) glutamate uptake and recycling via the glutamate-glutamine cycle, (b) increased glycolysis and shuttling of metabolites to neurons for oxidative phosphorylation, and (c) elevated $\mathrm{Ca}^{2+}$ signaling and release of vasoactive molecules for blood flow control. These responses ensure astrocytes tightly couple neuronal metabolic need with enhanced supply. Furthermore, astrocyte dysfunction may contribute to aberrant neuronal metabolism and neurovascular coupling in disease and injury and these pathways are promising therapeutic targets.

\section{ACKNOWLEDGMENTS}

Research is supported by the Canadian Institute of Health Research and Manitoba Health Research Council. Jillian L. Stobart was supported by a doctoral research award from the Canadian Institutes of Health Research.

R. J. (1998). Contribution of 20HETE to the vasodilator actions of nitric oxide in renal arteries. Am. J. Physiol. 275, F370-F378.

Amedee, T., Robert, A., and Coles, J. A. (1997). Potassium homeostasis and glial energy metabolism. Glia 21, 46-55.

Anderson, C. M., and Swanson, R. A. (2000). Astrocyte glutamate transport: review of properties, regulation, and physiological functions. Glia 32, 1-14.

Aoyama, K., Suh, S. W., Hamby, A. M., Liu, J., Chan, W. Y., Chen, Y., et al. (2006). Neuronal glutathione deficiency and age-dependent neurodegeneration in the EAAC1 deficient mouse. Nat. Neurosci. 9, 119-126.

Araque, A., Parpura, V., Sanzgiri, R. P., and Haydon, P. G. (1999). Tripartite synapses: glia, the unacknowledged partner. Trends Neurosci. 22, 208-215.

Arriza, J. L., Eliasof, S., Kavanaugh, M. P., and Amara, S. G. (1997). Excitatory amino acid transporter 5 , a retinal glutamate transporter coupled to a chloride conductance. Proc. Natl. Acad. Sci. U.S.A. 94, 4155-4160.

Attwell, D., Buchan, A. M., Charpak, S., Lauritzen, M., Macvicar, B. A., and Newman, E. A. (2010). Glial and neuronal control of brain blood flow. Nature 468, 232-243.
Aubert, A., Pellerin, L., Magistretti, P. J., and Costalat, R. (2007). A coherent neurobiological framework for functional neuroimaging provided by a model integrating compartmentalized energy metabolism. Proc. Natl. Acad. Sci. U.S.A. 104, 4188-4193.

Ballabh, P., Braun, A., and Nedergaard, M. (2004). The blood-brain barrier: an overview: structure, regulation, and clinical implications. Neurobiol. Dis. 16, 1-13.

Barkoudah, E., Jaggar, J. H., and Leffler, C. W. (2004). The permissive role of endothelial $\mathrm{NO}$ in CO-induced cerebrovascular dilation. Am. J. Physiol. Heart Circ. Physiol. 287, H1459-H1465.

Barros, L. F., and Deitmer, J. W. (2010). Glucose and lactate supply to the synapse. Brain Res. Rev. 63, 149-159.

Barros, L. F., San Martín, A., SoteloHitschfeld, T., Lerchundi, R., Fernández-Moncada, I., Ruminot, I., et al. (2013). Small is fast: astrocytic glucose and lactate metabolism at cellular resolution. Front. Cell Neurosci. 7:27. doi: 10 3389/fncel.2013.00027

Bedner, P., and Steinhauser, C. (2013). Altered Kir and gap junction channels in temporal lobe epilepsy. Neurochem. Int. doi: 10.1016/j.neuint.2013.01.011. [Epub ahead of print]. 
Bekar, L. K., He, W., and Nedergaard, M. (2008). Locus coeruleus alphaadrenergic-mediated activation of cortical astrocytes in vivo. Cereb. Cortex 18, 2789-2795

Bergersen, L., Waerhaug, O., Helm, J., Thomas, M., Laake, P., Davies, A. J., et al. (2001). A novel postsynaptic density protein: the monocarboxylate transporter MCT2 is co-localized with delta-glutamate receptors in postsynaptic densities of parallel fiber-Purkinje cell synapses. Exp. Brain Res. 136, 523-534.

Berkich, D. A., Ola, M. S., Cole, J., Sweatt, A. J., Hutson, S. M., and Lanoue, K. F. (2007). Mitochondrial transport proteins of the brain. J. Neurosci. Res. 85, 3367-3377.

Bernard-Helary, K., Lapouble, E., Ardourel, M., Hevor, T., and Cloix, J. F. (2000). Correlation between brain glycogen and convulsive state in mice submitted to methionine sulfoximine. Life Sci. 67, 1773-1781.

Bernardinelli, Y., Magistretti, P. J., and Chatton, J. Y. (2004). Astrocytes generate $\mathrm{Na}+$-mediated metabolic waves. Proc. Natl. Acad. Sci. U.S.A. 101, 14937-14942.

Bettler, B., Kaupmann, K., Mosbacher, J., and Gassmann, M. (2004). Molecular structure and physiological functions of $\mathrm{GABA}(\mathrm{B})$ receptors. Physiol. Rev. 84, 835-867.

Bezzi, P., Carmignoto, G., Pasti, L., Vesce, S., Rossi, D., Rizzini, B. L., et al. (1998). Prostaglandins stimulate calcium-dependent glutamate release in astrocytes. Nature 391, 281-285.

Bezzi, P., Gundersen, V., Galbete, J. L., Seifert, G., Steinhauser, C., Pilati, E., et al. (2004). Astrocytes contain a vesicular compartment that is competent for regulated exocytosis of glutamate. Nat. Neurosci. 7, 613-620.

Binder, D. K., and Steinhauser, C. (2006). Functional changes in astroglial cells in epilepsy. Glia 54, 358-368.

Bittar, P. G., Charnay, Y., Pellerin, L., Bouras, C., and Magistretti, P. J. (1996). Selective distribution of lactate dehydrogenase isoenzymes in neurons and astrocytes of human brain. J. Cereb. Blood Flow Metab. 16, 1079-1089.

Bittner, C. X., Valdebenito, R., Ruminot, I., Loaiza, A., Larenas, V., Sotelo-Hitschfeld, T., et al. (2011). Fast and reversible stimulation of astrocytic glycolysis by $\mathrm{K}+$ and a delayed and persistent effect of glutamate. J. Neurosci. 31, 4709-4713.
Blomstrand, F., Aberg, N. D., Eriksson, P. S., Hansson, E., and Ronnback, L. (1999). Extent of intercellular calcium wave propagation is related to gap junction permeability and level of connexin- 43 expression in astrocytes in primary cultures from four brain regions. Neuroscience 92, 255-265.

Bonde, C., Sarup, A., Schousboe, A., Gegelashvili, G., Zimmer, J., and Noraberg, J. (2003). Neurotoxic and neuroprotective effects of the glutamate transporter inhibitor DL-threo-beta-benzyloxyaspartate (DL-TBOA) during physiological and ischemia-like conditions. Neurochem. Int. 43, 371-380.

Bosley, T. M., Woodhams, P. L., Gordon, R. D., and Balazs, R. (1983). Effects of anoxia on the stimulated release of amino acid neurotransmitters in the cerebellum in vitro. J. Neurochem. 40, 189-201.

Bouzier-Sore, A. K., Merle, M., Magistretti, P. J., and Pellerin, L. (2002). Feeding active neurons: (re)emergence of a nursing role for astrocytes. J. Physiol. Paris 96, 273-282.

Braak, H., and Braak, E. (1988). Neuropil threads occur in dendrites of tangle-bearing nerve cells. Neuropathol. Appl. Neurobiol. 14, 39-44.

Bradley, K. K., Jaggar, J. H., Bonev, A. D., Heppner, T. J., Flynn, E. R., Nelson, M. T., et al. (1999). Kir2.1 encodes the inward rectifier potassium channel in rat arterial smooth muscle cells. J. Physiol. 515(Pt 3), 639-651.

Brian, J. E. Jr., Heistad, D. D., and Faraci, F. M. (1994). Effect of carbon monoxide on rabbit cerebral arteries. Stroke 25, 639-643. discussion: 643-634.

Broer, S., Rahman, B., Pellegri, G., Pellerin, L., Martin, J. L., Verleysdonk, S., et al. (1997). Comparison of lactate transport in astroglial cells and monocarboxylate transporter 1 (MCT 1) expressing Xenopus laevis oocytes. Expression of two different monocarboxylate transporters in astroglial cells and neurons. J. Biol. Chem. 272, 30096-30102.

Brookes, P. S., Yoon, Y., Robotham, J. L., Anders, M. W., and Sheu, S. S. (2004). Calcium, ATP, and ROS: a mitochondrial love-hate triangle. Am. J. Physiol. Cell Physiol. 287, C817-C833.

Brown, A. M., and Ransom, B. R. (2007). Astrocyte glycogen and brain energy metabolism. Glia 55, 1263-1271.
Brown, A. M., Sickmann, H. M., Fosgerau, K., Lund, T. M. Schousboe, A., Waagepetersen, H. S., et al. (2005). Astrocyte glycogen metabolism is required for neural activity during aglycemia or intense stimulation in mouse white matter. J. Neurosci. Res. 79, 74-80.

Brown, A. M., Tekkok, S. B., and Ransom, B. R. (2003). Glycogen regulation and functional role in mouse white matter. J. Physiol. 549, 501-512.

Bushong, E. A., Martone, M. E., Jones, Y. Z., and Ellisman, M. H. (2002). Protoplasmic astrocytes in CAl stratum radiatum occupy separate anatomical domains. J. Neurosci. 22, 183-192.

Caesar, K., Hashemi, P., Douhou, A., Bonvento, G., Boutelle, M. G., Walls, A. B., et al. (2008). Glutamate receptor-dependent increments in lactate, glucose and oxygen metabolism evoked in rat cerebellum in vivo. J. Physiol. 586, 1337-1349.

Cammer, W., and Zimmerman, T. R. Jr. (1982). Glycerolphosphate dehydrogenase, glucose-6-phosphate dehydrogenase, lactate dehydrogenase and carbonic anhydrase activities in oligodendrocytes and myelin: comparisons between species and CNS regions. Brain Res. 282, 21-26.

Cater, H. L., Benham, C. D. and Sundstrom, L. E. (2001). Neuroprotective role of monocarboxylate transport during glucose deprivation in slice cultures of rat hippocampus. J. Physiol. 531, 459-466.

Chan, B. S., Endo, S., Kanai, N., and Schuster, V. L. (2002). Identification of lactate as a driving force for prostanoid transport by prostaglandin transporter PGT. Am. J. Physiol. Renal Physiol. 282, F1097-F1102.

Chari, M., Lam, C. K., Wang, P. Y., and Lam, T. K. (2008). Activation of central lactate metabolism lowers glucose production in uncontrolled diabetes and diet-induced insulin resistance. Diabetes 57, 836-840.

Chari, M., Yang, C. S., Lam, C. K., Lee, K., Mighiu, P., Kokorovic, A., et al. (2011). Glucose transporter-1 in the hypothalamic glial cells mediates glucose sensing to regulate glucose production in vivo. Diabetes 60 , 1901-1906.

Chatton, J. Y., Marquet, P., and Magistretti, P. J. (2000). A quantitative analysis of Lglutamate-regulated $\mathrm{Na}+$ dynamics in mouse cortical astrocytes: implications for cellular bioenergetics. Eur. J. Neurosci. 12, 3843-3853.

Chaudhry, F. A., Schmitz, D., Reimer, R. J., Larsson, P., Gray, A. T., Nicoll, R., et al. (2002). Glutamine uptake by neurons: interaction of protons with system a transporters. J. Neurosci. 22, 62-72.

Chen, Y., and Swanson, R. A. (2003). The glutamate transporters EAAT2 and EAAT3 mediate cysteine uptake in cortical neuron cultures. J. Neurochem. 84, 1332-1339.

Chih, C. P., and Roberts, E. L. Jr. (2003). Energy substrates for neurons during neural activity: a critical review of the astrocyte-neuron lactate shuttle hypothesis. J. Cereb. Blood Flow Metab. 23, 1263-1281.

Cho, Y., and Bannai, S. (1990). Uptake of glutamate and cysteine in C- 6 glioma cells and in cultured astrocytes. J. Neurochem. 55, 2091-2097.

Cholet, N., Pellerin, L., Welker, E., Lacombe, P., Seylaz, J., Magistretti, P., et al. (2001). Local injection of antisense oligonucleotides targeted to the glial glutamate transporter GLAST decreases the metabolic response to somatosensory activation. J. Cereb. Blood Flow Metab. 21, 404-412.

Chow, S. K., Yu, D., Macdonald, C. L., Buibas, M., and Silva, G. A. (2010). Amyloid beta-peptide directly induces spontaneous calcium transients, delayed intercellular calcium waves and gliosis in rat cortical astrocytes. ASN Neuro 2:e00026. doi: 10.1042/AN20090035

Cloix, J. F., and Hevor, T. (2009). Epilepsy, regulation of brain energy metabolism and neurotransmission. Curr. Med. Chem. 16, 841-853.

Cloutier, M., Bolger, F. B., Lowry, J. P., and Wellstead, P. (2009). An integrative dynamic model of brain energy metabolism using in vivo neurochemical measurements. J. Comput. Neurosci. 27, 391-414.

Contreras, J. E., Sanchez, H. A., Eugenin, E. A., Speidel, D., Theis, M., Willecke, K., et al. (2002). Metabolic inhibition induces opening of unapposed connexin 43 gap junction hemichannels and reduces gap junctional communication in cortical astrocytes in culture. Proc. Natl. Acad. Sci. U.S.A. 99, 495-500.

Cotrina, M. L., Kang, J., Lin, J. H., Bueno, E., Hansen, T. W. He, L., et al. (1998). Astrocytic gap junctions remain open during ischemic conditions. J. Neurosci. 18, 2520-2537.

Csernansky, J. G., Bardgett, M. E., Sheline, Y. I., Morris, J. C., and Olney, J. W. (1996). CSF excitatory 
amino acids and severity of illness in Alzheimer's disease. Neurology 46, $1715-1720$.

D'Ambrosio, R. (2004). The role of glial membrane ion channels in seizures and epileptogenesis. Pharmacol. Ther. 103, 95-108.

Danbolt, N. C. (2001). Glutamate uptake. Prog. Neurobiol. 65, 1-105.

Del Zoppo, G. J. (2010). The neurovascular unit in the setting of stroke. J. Intern. Med. 267, 156-171.

Del Zoppo, G. J., and Mabuchi, T. (2003). Cerebral microvessel responses to focal ischemia. J. Cereb. Blood Flow Metab. 23, 879-894.

Devor, A., Tian, P., Nishimura, N., Teng, I. C., Hillman, E. M., Narayanan, S. N., et al. (2007). Suppressed neuronal activity and concurrent arteriolar vasoconstriction may explain negative blood oxygenation level-dependent signal. J. Neurosci. 27, 4452-4459.

Di Castro, M. A., Chuquet, J., Liaudet, N., Bhaukaurally, K., Santello, M., Bouvier, D., et al. (2011). Local Ca2+ detection and modulation of synaptic release by astrocytes. Nat. Neurosci. 14, 1276-1284.

Dinuzzo, M., Mangia, S., Maraviglia, B., and Giove, F. (2010). Changes in glucose uptake rather than lactate shuttle take center stage in subserving neuroenergetics: evidence from mathematical modeling. J. Cereb. Blood Flow Metab. 30, 586-602.

Dong, X. X., Wang, Y., and Qin, Z. H. (2009). Molecular mechanisms of excitotoxicity and their relevance to pathogenesis of neurodegenerative diseases. Acta Pharmacol. Sin. 30, 379-387.

Dorrance, A. M., Rupp, N., Pollock, D. M., Newman, J. W., Hammock, B. D., and Imig, J. D. (2005). An epoxide hydrolase inhibitor, 12-(3adamantan-1-yl-ureido)dodecanoic acid (AUDA), reduces ischemic cerebral infarct size in strokeprone spontaneously hypertensive rats. J. Cardiovasc. Pharmacol. 46, 842-848.

Dringen, R., Gebhardt, R., and Hamprecht, B. (1993). Glycogen in astrocytes: possible function as lactate supply for neighboring cells. Brain Res. 623, 208-214.

Dringen, R., and Hamprecht, B. (1993). Differences in glycogen metabolism in astroglia-rich primary cultures and sorbitol-selected astroglial cultures derived from mouse brain. Glia 8, 143-149.

Dudek, F. E., Patrylo, P. R., and Wuarin, J. P. (1999). Mechanisms of neuronal synchronization during epileptiform activity. Adv. Neurol. 79, 699-708.

Duffy, S., and Macvicar, B. A. (1995). Adrenergic calcium signaling in astrocyte networks within the hippocampal slice. J. Neurosci. 15, 5535-5550.

Dunn, K. M., and Nelson, M. T. (2010). Potassium channels and neurovascular coupling. Circ. J. 74, 608-616.

Dunn, K. M., Renic, M., Flasch, A. K., Harder, D. R., Falck, J., and Roman, R. J. (2008). Elevated production of 20-HETE in the cerebral vasculature contributes to severity of ischemic stroke and oxidative stress in spontaneously hypertensive rats. Am. J. Physiol. Heart Circ. Physiol. 295, H2455-H2465.

Earley, S., Heppner, T. J., Nelson, M. T., and Brayden, J. E. (2005). TRPV4 forms a novel Ca2+ signaling complex with ryanodine receptors and BKCa channels. Circ. Res. 97, 1270-1279.

Edmond, J., Robbins, R. A., Bergstrom, J. D., Cole, R. A., and De Vellis, J. (1987). Capacity for substrate utilization in oxidative metabolism by neurons, astrocytes, and oligodendrocytes from developing brain in primary culture. J. Neurosci. Res. 18, 551-561.

Eid, T., Lee, T. S., Thomas, M. J., Amiry-Moghaddam, M., Bjornsen, L. P., Spencer, D. D., et al. (2005). Loss of perivascular aquaporin 4 may underlie deficient water and $\mathrm{K}+$ homeostasis in the human epileptogenic hippocampus. Proc. Natl. Acad. Sci. U.S.A. 102, 1193-1198.

Eid, T., Thomas, M. J., Spencer, D. D., Runden-Pran, E., Lai, J. C., Malthankar, G. V., et al. (2004). Loss of glutamine synthetase in the human epileptogenic hippocampus: possible mechanism for raised extracellular glutamate in mesial temporal lobe epilepsy. Lancet 363, 28-37.

Engel, J. Jr., Brown, W. J., Kuhl, D. E., Phelps, M. E., Mazziotta, J. C., and Crandall, P. H. (1982). Pathological findings underlying focal temporal lobe hypometabolism in partial epilepsy. Ann. Neurol. 12, 518-528.

Engel, J. Jr., Kuhl, D. E., Phelps, M. E., Rausch, R., and Nuwer, M. (1983). Local cerebral metabolism during partial seizures. Neurology $33,400-413$.

Faff-Michalak, L., and Albrecht, J. (1993). Hyperammonemia and hepatic encephalopathy stimulate rat cerebral synaptic mitochondrial glutamate dehydrogenase activity specifically in the direction of glutamate oxidation. Brain Res. 618, 299-302.

Farkas, E., and Luiten, P. G. (2001) Cerebral microvascular pathology in aging and Alzheimer's disease. Prog. Neurobiol. 64, 575-611.

Filosa, J. A., Bonev, A. D., and Nelson, M. T. (2004). Calcium dynamics in cortical astrocytes and arterioles during neurovascular coupling. Circ. Res. 95, e73-e81.

Filosa, J. A., Bonev, A. D., Straub, S. V., Meredith, A. L., Wilkerson, M. K., Aldrich, R. W., et al. (2006) Local potassium signaling couples neuronal activity to vasodilation in the brain. Nat. Neurosci. 9, 1397-1403.

Fiumana, E., Parfenova, H., Jaggar, J. H., and Leffler, C. W. (2003). Carbon monoxide mediates vasodilator effects of glutamate in isolated pressurized cerebral arterioles of newborn pigs. Am. J. Physiol. Heart Circ. Physiol. 284, H1073-H1079.

Fleming, I. (2004). Cytochrome P450 epoxygenases as EDHF synthase(s). Pharmacol. Res. 49, 525-533.

Fonnum, F. (1984). Glutamate: a neurotransmitter in mammalian brain. J. Neurochem. 42, 1-11.

Fossat, P., Turpin, F. R., Sacchi, S. Dulong, J., Shi, T., Rivet, J. M., et al. (2012). Glial D-serine gates NMDA receptors at excitatory synapses in prefrontal cortex. Cereb. Cortex 22, 595-606.

Fotheringham, J., Donati, D., Akhyani, N., Fogdell-Hahn, A., Vortmeyer, A., Heiss, J. D., et al. (2007). Association of human herpesvirus$6 \mathrm{~B}$ with mesial temporal lobe epilepsy. PLoS Med. 4:e180. doi: 10. 1371/journal.pmed.0040180

Fowler, J. C. (1993). Glucose deprivation results in a lactate preventable increase in adenosine and depression of synaptic transmission in rat hippocampal slices. J. Neurochem. $60,572-576$.

Fremeau, R. T. Jr., Kam, K., Qureshi, T., Johnson, J., Copenhagen, D. R., Storm-Mathisen, J., et al. (2004) Vesicular glutamate transporters 1 and 2 target to functionally distinct synaptic release sites. Science 304, 1815-1819.

Fujimoto, Y., Uno, E., and Sakuma, S. (2004). Effects of reactive oxygen and nitrogen species on cyclooxygenase-1 and -2 activities. Prostaglandins Leukot. Essent. Fatty Acids 71, 335-340.

Fuller, S., Munch, G., and Steele, M. (2009). Activated astrocytes: a therapeutic target in Alzheimer's disease? Expert Rev. Neurother. 9, 1585-1594.
Furuta, A., Martin, L. J., Lin, C. L., Dykes-Hoberg, M., and Rothstein, J. D. (1997). Cellular and synaptic localization of the neuronal glutamate transporters excitatory amino acid transporter 3 and 4 . Neuroscience 81, 1031-1042.

Garriga-Canut, M., Schoenike, B., Qazi, R., Bergendahl, K., Daley, T. J., Pfender, R. M., et al. (2006). 2Deoxy-D-glucose reduces epilepsy progression by NRSF-CtBPdependent metabolic regulation of chromatin structure. Nat. Neurosci. 9, 1382-1387.

Gebremedhin, D., Ma, Y. H., Falck, J. R., Roman, R. J., Vanrollins, M., and Harder, D. R. (1992). Mechanism of action of cerebral epoxyeicosatrienoic acids on cerebral arterial smooth muscle. Am. J. Physiol. 263, H519-H525.

Gerhart, D. Z., Enerson, B. E., Zhdankina, O. Y., Leino, R. L., and Drewes, L. R. (1998). Expression of the monocarboxylate transporter MCT2 by rat brain glia. Glia 22 , 272-281.

Ghosh, A., Cheung, Y. Y., Mansfield, B. C., and Chou, J. Y. (2005). Brain contains a functional glucose-6phosphatase complex capable of endogenous glucose production. J. Biol. Chem. 280, 11114-11119.

Giaume, C., and McCarthy, K. D. (1996). Control of gap-junctional communication in astrocytic networks. Trends Neurosci. 19, 319-325.

Gibbs, M. E., Anderson, D. G., and Hertz, L. (2006). Inhibition of glycogenolysis in astrocytes interrupts memory consolidation in young chickens. Glia 54, 214-222.

Gibbs, M. E., Gibbs, Z., and Hertz, L. (2009). Rescue of Abeta(1-42)induced memory impairment in day-old chick by facilitation of astrocytic oxidative metabolism: implications for Alzheimer's disease. J. Neurochem. 109(Suppl. 1), 230-236.

Gibbs, M. E., and Hertz, L. (2008). Inhibition of astrocytic energy metabolism by D-lactate exposure impairs memory. Neurochem. Int. 52, 1012-1018.

Gibbs, M. E., Lloyd, H. G., Santa, T. and Hertz, L. (2007). Glycogen is a preferred glutamate precursor during learning in 1-day-old chick: biochemical and behavioral evidence. J. Neurosci. Res. 85, 3326-3333.

Girouard, H., Bonev, A. D., Hannah, R. M., Meredith, A., Aldrich, R. W. and Nelson, M. T. (2010). Astrocytic endfoot $\mathrm{Ca} 2+$ and $\mathrm{BK}$ channels determine both arteriolar dilation 
and constriction. Proc. Natl. Acad. Sci. U.S.A. 107, 3811-3816.

Goldberg, M. P., Monyer, H., and Choi, D. W. (1988). Hypoxic neuronal injury in vitro depends on extracellular glutamine. Neurosci. Lett. 94, 52-57.

Gomez-Galan, M., Makarova, J., Llorente-Folch, I., Saheki, T., Pardo, B., Satrustegui, J., et al. (2012). Altered postnatal development of cortico-hippocampal neuronal electric activity in mice deficient for the mitochondrial aspartate-glutamate transporter. J. Cereb. Blood Flow Metab. 32, 306-317.

Gomez-Gonzalo, M., Losi, G., Brondi, M., Uva, L., Sato, S. S., De Curtis, M., et al. (2011). Ictal but not interictal epileptic discharges activate astrocyte endfeet and elicit cerebral arteriole responses. Front. Cell Neurosci. 5:8. doi: 10.3389/fncel. 2011.00008

Gomez-Gonzalo, M., Losi, G., Chiavegato, A., Zonta, M., Cammarota, M., Brondi, M., et al. (2010). An excitatory loop with astrocytes contributes to drive neurons to seizure threshold. PLoS Biol. 8:e1000352. doi: 10.1371/ journal.pbio. 1000352

Gordon, G. R., Choi, H. B., Rungta, R. L., Ellis-Davies, G. C., and Macvicar, B. A. (2008). Brain metabolism dictates the polarity of astrocyte control over arterioles. Nature 456, 745-749.

Gorovits, R., Avidan, N., Avisar, N., Shaked, I., and Vardimon, L. (1997). Glutamine synthetase protects against neuronal degeneration in injured retinal tissue. Proc. Natl. Acad. Sci. U.S.A. 94, 7024-7029.

Gosejacob, D., Dublin, P., Bedner, P., Huttmann, K., Zhang, J., Tress, O., et al. (2011). Role of astroglial connexin30 in hippocampal gap junction coupling. Glia 59, 511-519.

Grill, H. J., Schwartz, M. W., Kaplan, J. M., Foxhall, J. S., Breininger, J., and Baskin, D. G. (2002). Evidence that the caudal brainstem is a target for the inhibitory effect of leptin on food intake. Endocrinology 143, 239-246.

Guthrie, P. B., Knappenberger, J., Segal, M., Bennett, M. V., Charles, A. C., and Kater, S. B. (1999). ATP released from astrocytes mediates glial calcium waves. J. Neurosci. 19, 520-528.

Haas, B., Schipke, C. G., Peters, O., Sohl, G., Willecke, K., and Kettenmann, H. (2006). Activitydependent ATP-waves in the mouse neocortex are independent from astrocytic calcium waves. Cereb. Cortex 16, 237-246.
Haberg, A., Qu, H., Saether, O., Unsgard, G., Haraldseth, O., and Sonnewald, U. (2001). Differences in neurotransmitter synthesis and intermediary metabolism between glutamatergic and GABAergic neurons during 4 hours of middle cerebral artery occlusion in the rat: the role of astrocytes in neuronal survival. J. Cereb. Blood Flow Metab. 21, 1451-1463.

Halassa, M. M., Fellin, T., Takano, H., Dong, J. H., and Haydon, P. G. (2007). Synaptic islands defined by the territory of a single astrocyte. J. Neurosci. 27, 6473-6477.

Harder, D. R., Narayanan, J., Birks, E. K., Liard, J. F., Imig, J. D., Lombard, J. H., et al. (1996). Identification of a putative microvascular oxygen sensor. Circ. Res. 79, 54-61.

Hassinger, T. D., Guthrie, P. B., Atkinson, P. B., Bennett, M. V., and Kater, S. B. (1996). An extracellular signaling component in propagation of astrocytic calcium waves. Proc. Natl. Acad. Sci. U.S.A. 93, 13268-13273.

Haughey, N. J., and Mattson, M. P. (2003). Alzheimer's amyloid beta-peptide enhances ATP/gap junction-mediated calciumwave propagation in astrocytes. Neuromol. Med. 3, 173-180.

He, Y., Janssen, W. G., Rothstein, J. D., and Morrison, J. H. (2000). Differential synaptic localization of the glutamate transporter EAAC1 and glutamate receptor subunit GluR2 in the rat hippocampus. J. Comp. Neurol. 418, 255-269.

Henneberger, C., Papouin, T., Oliet, S. H., and Rusakov, D. A. (2010) Long-term potentiation depends on release of $\mathrm{D}$-serine from astrocytes. Nature 463, 232-236.

Henneberger, C., and Rusakov, D. A. (2010). Synaptic plasticity and $\mathrm{Ca} 2+$ signalling in astrocytes. Neuron Glia Biol. 6, 141-146.

Herrero-Mendez, A., Almeida, A., Fernandez, E., Maestre, C., Moncada, S., and Bolanos, J. P. (2009). The bioenergetic and antioxidant status of neurons is controlled by continuous degradation of a key glycolytic enzyme by APC/C-Cdh1. Nat. Cell Biol. 11, 747-752.

Hertz, L. (2003). Astrocytic amino acid metabolism under control conditions and during oxygen and/or glucose deprivation. Neurochem. Res. 28, 243-258.

Hertz, L. (2008). Bioenergetics of cerebral ischemia: a cellular perspective. Neuropharmacology 55, 289-309.

Hertz, L. (2011). Astrocytic energy metabolism and glutamate formation-relevance for 13CNMR spectroscopy and importance of cytosolic/mitochondrial trafficking. Magn. Reson. Imaging 29, 1319-1329.

Hertz, L., and Hertz, E. (2003) Cataplerotic TCA cycle flux determined as glutamate-sustained oxygen consumption in primary cultures of astrocytes. Neurochem. Int. 43, 355-361.

Hertz, L., Peng, L., and Dienel, G. A. (2007). Energy metabolism in astrocytes: high rate of oxidative metabolism and spatiotemporal dependence on glycolysis/glycogenolysis. J. Cereb. Blood Flow Metab. 27, 219-249.

Hertz, L., Peng, L., and Lai, J. C. (1998) Functional studies in cultured astrocytes. Methods 16, 293-310.

Hertz, L., and Zielke, H. R. (2004). Astrocytic control of glutamatergic activity: astrocytes as stars of the show. Trends Neurosci. 27, 735-743.

Higashimori, H., Blanco, V. M., Tuniki, V. R., Falck, J. R., and Filosa, J. A. (2010). Role of epoxyeicosatrienoic acids as autocrine metabolites in glutamate-mediated $\mathrm{K}+\mathrm{sig}-$ naling in perivascular astrocytes. Am. J. Physiol. Cell Physiol. 299, C1068-C1078.

Hillered, L., Hallstrom, A., Segersvard, S., Persson, L., and Ungerstedt, U. (1989). Dynamics of extracellular metabolites in the striatum after middle cerebral artery occlusion in the rat monitored by intracerebral microdialysis. J. Cereb. Blood Flow Metab. 9, 607-616.

Hirrlinger, J., and Dringen, R. (2010). The cytosolic redox state of astrocytes: maintenance, regulation and functional implications for metabolite trafficking. Brain Res. Rev. 63 177-188.

Hiyama, T. Y., Watanabe, E., Okado H., and Noda, M. (2004). The subfornical organ is the primary locus of sodium-level sensing by $\mathrm{Na}(\mathrm{x})$ sodium channels for the control of salt-intake behavior. J. Neurosci. 24, 9276-9281.

Hiyama, T. Y., Watanabe, E., Ono, K., Inenaga, K., Tamkun, M. M., Yoshida, S., et al. (2002). $\mathrm{Na}(\mathrm{x})$ channel involved in CNS sodiumlevel sensing. Nat. Neurosci. 5, 511-512.

Holt, D. C., Fedinec, A. L., Vaughn, A. N., and Leffler, C. W. (2007). Age and species dependence of pial arteriolar responses to topical carbon monoxide in vivo. Exp. Biol. Med. (Maywood) 232, 1465-1469.

Hu, Y., and Wilson, G. S. (1997). A temporary local energy pool coupled to neuronal activity: fluctuations of extracellular lactate levels in rat brain monitored with rapidresponse enzyme-based sensor. J. Neurochem. 69, 1484-1490.

Iadecola, C. (2004). Neurovascular regulation in the normal brain and in Alzheimer's disease. Nat. Rev. Neurosci. 5, 347-360.

Idestrup, C. P., and Salter, M. W. (1998). P2Y and P2U receptors differentially release intracellular $\mathrm{Ca} 2+$ via the phospholipase c/inositol 1, 4, 5-triphosphate pathway in astrocytes from the dorsal spinal cord. Neuroscience 86 , 913-923.

Ignarro, L. J., Cirino, G., Casini, A., and Napoli, C. (1999). Nitric oxide as a signaling molecule in the vascular system: an overview. J. Cardiovasc. Pharmacol. 34, 879-886.

Imig, J. D., and Hammock, B. D. (2009). Soluble epoxide hydrolase as a therapeutic target for cardiovascular diseases. Nat. Rev. Drug Discov. 8, 794-805.

Ishikawa, M., Kajimura, M., Adachi, T., Maruyama, K., Makino, N., Goda, N., et al. (2005). Carbon monoxide from heme oxygenase-2 Is a tonic regulator against $\mathrm{NO}$ dependent vasodilatation in the adult rat cerebral microcirculation. Circ. Res. 97, e104-e114.

Izumi, Y., Katsuki, H., and Zorumski, C. F. (1997). Monocarboxylates (pyruvate and lactate) as alternative energy substrates for the induction of long-term potentiation in rat hippocampal slices. Neurosci. Lett. 232, 17-20

Jackson, M., Song, W., Liu, M. Y., Jin, L., Dykes-Hoberg, M., Lin, C. I., et al. (2001). Modulation of the neuronal glutamate transporter EAAT4 by two interacting proteins. Nature 410, 89-93.

Jaggar, J. H., Leffler, C. W., Cheranov, S. Y., Tcheranova, D., E, S., and Cheng, X. (2002). Carbon monoxide dilates cerebral arterioles by enhancing the coupling of $\mathrm{Ca} 2+$ sparks to $\mathrm{Ca} 2+$-activated $\mathrm{K}+$ channels. Circ Res. 91, 610-617.

Jamieson, D., and Vandenbrenk, H. A. (1963). Measurement of oxygen tensions in cerebral tissues of rats exposed to high pressures of oxygen. J. Appl. Physiol. 18, 869-876.

Jimenez-Jimenez, F. J., Molina, J. A. Gomez, P., Vargas, C., De Bustos, F., Benito-Leon, J., et al. (1998). Neurotransmitter amino acids in cerebrospinal fluid of patients with Alzheimer's disease. J. Neural Transm. 105, 269-277.

Jourdain, P., Bergersen, L. H. Bhaukaurally, K., Bezzi, P., Santello, M., Domercq, M., et al. (2007). 
Glutamate exocytosis from astrocytes controls synaptic strength. Nat. Neurosci. 10, 331-339.

Juranek, I., Suzuki, H., and Yamamoto, S. (1999). Affinities of various mammalian arachidonate lipoxygenases and cyclooxygenases for molecular oxygen as substrate. Biochim. Biophys. Acta 1436, 509-518.

Juurlink, B. H. (1997). Response of glial cells to ischemia: roles of reactive oxygen species and glutathione. Neurosci. Biobehav. Rev. 21, 151-166.

Kacem, K., Lacombe, P., Seylaz, J., and Bonvento, G. (1998). Structural organization of the perivascular astrocyte endfeet and their relationship with the endothelial glucose transporter: a confocal microscopy study. Glia 23, 1-10.

Kang, J., Jiang, L., Goldman, S. A., and Nedergaard, M. (1998). Astrocyte-mediated potentiation of inhibitory synaptic transmission. Nat. Neurosci. 1, 683-692.

Kanu, A., Gilpin, D., Fedinec, A. L., and Leffler, C. W. (2006). Cyclooxygenase products stimulate carbon monoxide production by piglet cerebral microvessels. Exp. Biol. Med. (Maywood) 231, 181-185.

Kanu, A., and Leffler, C. W. (2009). Roles of glia limitans astrocytes and carbon monoxide in adenosine diphosphate-induced pial arteriolar dilation in newborn pigs. Stroke 40, 930-935.

Kanu, A., and Leffler, C. W. (2011). Arachidonic acid- and prostaglandin E2-induced cerebral vasodilation is mediated by carbon monoxide, independent of reactive oxygen species in piglets. Am. J. Physiol. Heart Circ. Physiol. 301, H2482-H2487.

Kasischke, K. A. (2008). A new pathway for lactate production in the CNS. J. Physiol. 586, 1207-1208.

Kasischke, K. A., Vishwasrao, H. D. Fisher, P. J., Zipfel, W. R., and Webb, W. W. (2004). Neural activity triggers neuronal oxidative metabolism followed by astrocytic glycolysis. Science 305, 99-103.

Kimelberg, H. K., Goderie, S. K., Higman, S., Pang, S., and Waniewski, R. A. (1990). Swellinginduced release of glutamate, aspartate, and taurine from astrocyte cultures. J. Neurosci. 10, 1583-1591.

Kishore, P., Boucai, L., Zhang, K., Li, W., Koppaka, S., Kehlenbrink, S., et al. (2011). Activation of K(ATP) channels suppresses glucose production in humans. J. Clin. Invest. 121, 4916-4920.
Knecht, K. R., Milam, S., Wilkinson, D. A., Fedinec, A. L., and Leffler, C. W. (2010). Time-dependent action of carbon monoxide on the newborn cerebrovascular circulation. Am. J. Physiol. Heart Circ. Physiol. 299, H70-H75.

Knot, H. J., and Nelson, M. T. (1998). Regulation of arterial diameter and wall $[\mathrm{Ca} 2+]$ in cerebral arteries of rat by membrane potential and intravascular pressure. J. Physiol. 508(Pt 1), 199-209.

Knot, H. J., Zimmermann, P. A., and Nelson, M. T. (1996). Extracellular $\mathrm{K}(+)$-induced hyperpolarizations and dilatations of rat coronary and cerebral arteries involve inward rectifier $\mathrm{K}(+)$ channels. J. Physiol. 492(Pt 2), 419-430.

Kofuji, P., and Newman, E. A. (2004). Potassium buffering in the central nervous system. Neuroscience 129, 1045-1056.

Koizumi, J. (1974). Glycogen in the central nervous system. Prog. Histochem. Cytochem. 6, 1-37.

Kovacs, R., Heinemann, U., and Steinhauser, C. (2012). Mechanisms underlying blood-brain barrier dysfunction in brain pathology and epileptogenesis: role of astroglia. Epilepsia 53(Suppl. 6), 53-59.

Kuchibhotla, K. V., Lattarulo, C. R., Hyman, B. T., and Bacskai, B. J. (2009). Synchronous hyperactivity and intercellular calcium waves in astrocytes in Alzheimer mice. Science 323, 1211-1215.

Kuhl, D. E., Engel, J. Jr., Phelps, M. E., and Selin, C. (1980). Epileptic patterns of local cerebral metabolism and perfusion in humans determined by emission computed tomography of 18FDG and 13NH3. Ann. Neurol. 8, 348-360.

Kvamme, E., Roberg, B., and Torgner, I. A. (2000). Phosphate-activated glutaminase and mitochondrial glutamine transport in the brain. Neurochem. Res. 25, 1407-1419.

Lam, T. K., Gutierrez-Juarez, R., Pocai, A., Bhanot, S., Tso, P., Schwartz, G. J., et al. (2007). Brain glucose metabolism controls the hepatic secretion of triglyceriderich lipoproteins. Nat. Med. 13, 171-180.

Lam, T. K., Gutierrez-Juarez, R. Pocai, A., and Rossetti, L. (2005) Regulation of blood glucose by hypothalamic pyruvate metabolism. Science 309, 943-947.

Langer, J., and Rose, C. R. (2009). Synaptically induced sodium signals in hippocampal astrocytes in situ. J. Physiol. 587, 5859-5877.
Leffler, C. W., Balabanova, L., Fedinec, A. L., and Parfenova, H. (2005a). Nitric oxide increases carbon monoxide production by piglet cerebral microvessels. Am. J. Physiol. Heart Circ. Physiol. 289, H1442-H1447.

Leffler, C. W., Fedinec, A. L., Parfenova, H., and Jaggar, J. H. (2005b). Permissive contributions of $\mathrm{NO}$ and prostacyclin in CO-induced cerebrovascular dilation in piglets. Am. J. Physiol. Heart Circ. Physiol. 289, H432-H438.

Leffler, C. W., Balabanova, L., Fedinec, A. L., Waters, C. M., and Parfenova, H. (2003). Mechanism of glutamate stimulation of $\mathrm{CO}$ production in cerebral microvessels. Am. J. Physiol. Heart Circ. Physiol. 285, H74-H80.

Leffler, C. W., Busija, D. W., Mirro, R. Armstead, W. M., and Beasley, D. G. (1989). Effects of ischemia on brain blood flow and oxygen consumption of newborn pigs. Am. J. Physiol. 257, H1917-H1926.

Leffler, C. W., Nasjletti, A., Yu, C. Johnson, R. A., Fedinec, A. L., and Walker, N. (1999). Carbon monoxide and cerebral microvascular tone in newborn pigs. Am. J. Physiol. 276, H1641-H1646.

Leffler, C. W., Parfenova, H., Fedinec, A. L., Basuroy, S., and Tcheranova, D. (2006a). Contributions of astrocytes and $\mathrm{CO}$ to pial arteriolar dilation to glutamate in newborn pigs. Am. J. Physiol. Heart Circ. Physiol. 291, H2897-H2904.

Leffler, C. W., Parfenova, H., Jaggar, J. H., and Wang, R. (2006b). Carbon monoxide and hydrogen sulfide: gaseous messengers in cerebrovascular circulation. J. Appl. Physiol. 100, 1065-1076.

Leffler, C. W., Parfenova, H., and Jaggar, J. H. (2011). Carbon monoxide as an endogenous vascular modulator. Am. J. Physiol. Heart Circ. Physiol. 301, H1-H11.

Lemire, J., Mailloux, R. J., and Appanna, V. D. (2008) Mitochondrial lactate dehydrogenase is involved in oxidative-energy metabolism in human astrocytoma cells (CCF-STTG1). PLoS ONE 3:e1550. doi: 10.1371/journal.pone. 0001550

Li, A., Xi, Q., Umstot, E. S., Bellner, L., Schwartzman, M. L., Jaggar, J. H., et al. (2008). Astrocyte-derived $\mathrm{CO}$ is a diffusible messenger that mediates glutamate-induced cerebral arteriolar dilation by activating smooth muscle Cell KCa channels. Circ. Res. 102, 234-241.

Li, B., Hertz, L., and Peng, L. (2012). Aralar mRNA and protein levels in neurons and astrocytes freshly isolated from young and adult mouse brain and in maturing cultured astrocytes. Neurochem. Int. 61, 1325-1332.

Li, P. A., and Siesjo, B. K. (1997). Role of hyperglycaemia-related acidosis in ischaemic brain damage. Acta Physiol. Scand. 161, 567-580.

Li, S., Mallory, M., Alford, M., Tanaka, S., and Masliah, E. (1997). Glutamate transporter alterations in Alzheimer disease are possibly associated with abnormal APP expression. J. Neuropathol. Exp. Neurol. 56, 901-911.

Lindauer, U., Leithner, C., Kaasch, H., Rohrer, B., Foddis, M., Fuchtemeier, M., et al. (2010). Neurovascular coupling in rat brain operates independent of hemoglobin deoxygenation. J. Cereb. Blood Flow Metab. 30, 757-768.

Liu, M., and Alkayed, N. J. (2005). Hypoxic preconditioning and tolerance via hypoxia inducible factor (HIF) 1alpha-linked induction of P450 2C11 epoxygenase in astrocytes. J. Cereb. Blood Flow Metab. 25, 939-948.

Liu, X., Li, C., Falck, J. R., Roman, R. J., Harder, D. R., and Koehler, R. C. (2008). Interaction of nitric oxide, 20-HETE, and EETs during functional hyperemia in whisker barrel cortex. Am. J. Physiol. Heart Circ. Physiol. 295, H619-H631.

Liu, X., Li, C., Gebremedhin, D., Hwang, S. H., Hammock, B. D., Falck, J. R., et al. (2011). Epoxyeicosatrienoic aciddependent cerebral vasodilation evoked by metabotropic glutamate receptor activation in vivo. Am. J. Physiol. Heart Circ. Physiol. 301, H373-H381.

Llorente-Folch, I., Sahun, I., Contreras, L., Casarejos, M. J., Grau, J. M., Saheki, T., et al. (2013). AGC1malate aspartate shuttle activity is critical for dopamine handling in the nigrostriatal pathway. J. Neurochem. 124, 347-362.

Loaiza, A., Porras, O. H., and Barros, L. F. (2003). Glutamate triggers rapid glucose transport stimulation in astrocytes as evidenced by real-time confocal microscopy. J. Neurosci. 23, 7337-7342.

Magistretti, P. J. (2006). Neuron-glia metabolic coupling and plasticity. J. Exp. Biol. 209, 2304-2311.

Magistretti, P. J., and Pellerin, L. (1999). Cellular mechanisms of brain energy metabolism and their relevance to functional brain imaging. Philos. Trans. R. Soc. Lond. B Biol. Sci. 354, 1155-1163.

Magistretti, P. J., Pellerin, L., Rothman, D. L., and Shulman, R. G. (1999) 
Energy on demand. Science 283, 496-497.

Mangia, S., Garreffa, G., Bianciardi, M., Giove, F., Di Salle, F., and Maraviglia, B. (2003). The aerobic brain: lactate decrease at the onset of neural activity. Neuroscience 118, $7-10$.

Mangia, S., Simpson, I. A., Vannucci, S. J., and Carruthers, A. (2009). The in vivo neuron-to-astrocyte lactate shuttle in human brain: evidence from modeling of measured lactate levels during visual stimulation. J. Neurochem. 109(Suppl. 1), $55-62$.

Mangia, S., Tkac, I., Gruetter, R., Van De Moortele, P. F., Maraviglia, B., and Ugurbil, K. (2007). Sustained neuronal activation raises oxidative metabolism to a new steady-state level: evidence from $1 \mathrm{H}$ NMR spectroscopy in the human visual cortex. J. Cereb. Blood Flow Metab. 27, 1055-1063.

Martinez-Hernandez, A., Bell, K. P., and Norenberg, M. D. (1977). Glutamine synthetase: glial localization in brain. Science 195, 1356-1358.

Masliah, E., Alford, M., Mallory, M., Rockenstein, E., Moechars, D., and Van Leuven, F. (2000). Abnormal glutamate transport function in mutant amyloid precursor protein transgenic mice. Exp. Neurol. 163, 381-387.

Maus, M., Marin, P., Israel, M., Glowinski, J., and Premont, J. (1999). Pyruvate and lactate protect striatal neurons against N-methyl$\mathrm{D}$-aspartate-induced neurotoxicity. Eur. J. Neurosci. 11, 3215-3224.

McCaslin, A. F., Chen, B. R., Radosevich, A. J., Cauli, B., and Hillman, E. M. (2011). In vivo 3D morphology of astrocytevasculature interactions in the somatosensory cortex: implications for neurovascular coupling. J. Cereb. Blood Flow Metab. 31, 795-806.

McCormick, D. A., and Contreras, D. (2001). On the cellular and network bases of epileptic seizures. Аnnu. Rev. Physiol. 63, 815-846.

McKenna, M. C. (2007). The glutamate-glutamine cycle is not stoichiometric: fates of glutamate in brain. J. Neurosci. Res. 85, 3347-3358.

McKenna, M. C., Hopkins, I. B., Lindauer, S. L., and Bamford, P. (2006a). Aspartate aminotransferase in synaptic and nonsynaptic mitochondria: differential effect of compounds that influence transient hetero-enzyme complex (metabolon) formation. Neurochem. Int. 48, 629-636.
McKenna, M. C., Waagepetersen, H. S., Schousboe, A., and Sonnewald, U. (2006b). Neuronal and astrocytic shuttle mechanisms for cytosolicmitochondrial transfer of reducing equivalents: current evidence and pharmacological tools. Biochem. Pharmacol. 71, 399-407.

McKenna, M. C., Tildon, J. T., Stevenson, J. H., Boatright, R. and Huang, S. (1993). Regulation of energy metabolism in synaptic terminals and cultured rat brain astrocytes: differences revealed using aminooxyacetate. Dev. Neurosci. 15, 320-329.

McKhann, G., Drachman, D., Folstein, M., Katzman, R., Price, D., and Stadlan, E. M. (1984). Clinical diagnosis of Alzheimer's disease: report of the NINCDS-ADRDA Work Group under the auspices of Department of Health and Human Services Task Force on Alzheimer's Disease. Neurology 34, 939-944.

Meier, S. D., Kafitz, K. W., and Rose, C. R. (2008). Developmental profile and mechanisms of GABA-induced calcium signaling in hippocampal astrocytes. Glia 56, 1127-1137.

Mentis, M. J., Horwitz, B., Grady, C. L., Alexander, G. E., Vanmeter, J. W., Maisog, J. M., et al. (1996). Visual cortical dysfunction in Alzheimer's disease evaluated with a temporally graded "stress test" during PET. Am. J. Psychiatry 153, 32-40.

Merlini, M., Meyer, E. P., UlmannSchuler, A., and Nitsch, R. M. (2011). Vascular beta-amyloid and early astrocyte alterations impair cerebrovascular function and cerebral metabolism in transgenic arcAbeta mice. Acta Neuropathol. 122, 293-311.

Merz, P. A., Wisniewski, H. M., Somerville, R. A., Bobin, S. A. Masters, C. L., and Iqbal, K. (1983). Ultrastructural morphology of amyloid fibrils from neuritic and amyloid plaques. Acta Neuropathol. 60, 113-124.

Metea, M. R., Kofuji, P., and Newman, E. A. (2007). Neurovascular coupling is not mediated by potassium siphoning from glial cells. J. Neurosci. 27, 2468-2471.

Metea, M. R., and Newman, E. A. (2006). Glial cells dilate and constrict blood vessels: a mechanism of neurovascular coupling. J. Neurosci. 26, 2862-2870.

Metzger, H., Erdmann, W., and Thews, G. (1971). Effect of short periods of hypoxia, hyperoxia, and hypercapnia on brain O 2 supply. J. Appl. Physiol. 31, 751-759.

Mishra, A., Hamid, A., and Newman, E. A. (2011). Oxygen modulation of neurovascular coupling in the retina. Proc. Natl. Acad. Sci. U.S.A. 108, 17827-17831.

Mishra, A., and Newman, E. A. (2010). Inhibition of inducible nitric oxide synthase reverses the loss of functional hyperemia in diabetic retinopathy. Glia 58, 1996-2004.

Miura, H., and Gutterman, D. D. (1998). Human coronary arteriolar dilation to arachidonic acid depends on cytochrome P-450 monooxygenase and $\mathrm{Ca} 2+$-activated $\mathrm{K}+$ channels. Circ. Res. 83, 501-507.

Miyata, N., Seki, T., Tanaka, Y., Omura, T., Taniguchi, K., Doi, M., et al. (2005). Beneficial effects of new 20-hydroxyeicosatetraenoic acid synthesis inhibitor TS-011 [N-(3-chloro-4-morpholin4-yl) phenyl-N'-hydroxyimido formamide], on hemorrhagic and ischemic stroke. J. Pharmacol. Exp. Ther. 314, 77-85.

Morikawa, T., Kajimura, M., Nakamura, T., Hishiki, T., Nakanishi, T., Yukutake, Y., et al. (2012). Hypoxic regulation of the cerebral microcirculation is mediated by a carbon monoxidesensitive hydrogen sulfide pathway. Proc. Natl. Acad. Sci. U.S.A. 109, 1293-1298.

Mosconi, L., Pupi, A., and De Leon, M. J. (2008). Brain glucose hypometabolism and oxidative stress in preclinical Alzheimer's disease. Ann. N.Y. Acad. Sci. 1147 180-195.

Mothet, J. P., Pollegioni, L., Ouanounou, G., Martineau, M., Fossier, P., and Baux, G. (2005). Glutamate receptor activation triggers a calcium-dependent and SNARE protein-dependent release of the gliotransmitter D-serine. Proc. Natl. Acad. Sci. U.S.A. 102, 5606-5611.

Mulligan, S. J., and Macvicar, B. A. (2004). Calcium transients in astrocyte endfeet cause cerebrovascular constrictions. Nature 431, 195-199.

Nagao, S., Kwak, S., and Kanazawa, I. (1997). EAAT4, a glutamate transporter with properties of a chloride channel, is predominantly localized in Purkinje cell dendrites, and forms parasagittal compartments in rat cerebellum. Neuroscience 78 929-933.

Navarrete, M., and Araque, A. (2008). Endocannabinoids mediate neuronastrocyte communication. Neuron $57,883-893$.

Navarrete, M., and Araque, A. (2010). Endocannabinoids potentiate synaptic transmission through stimulation of astrocytes. Neuron $68,113-126$.
Navarrete, M., Perea, G., Fernandez De Sevilla, D., Gomez-Gonzalo, M., Nunez, A., Martin, E. D., et al. (2012). Astrocytes mediate in vivo cholinergic-induced synaptic plasticity. PLoS Biol. 10:e1001259. doi: 10.1371/journal.pbio.1001259

Nedergaard, M., and Verkhratsky, A. (2012). Artifact versus reality-how astrocytes contribute to synaptic events. Glia 60, 1013-1023.

Newman, E. A., Frambach, D. A., and Odette, L. L. (1984). Control of extracellular potassium levels by retinal glial cell $\mathrm{K}+$ siphoning. Science 225, 1174-1175.

Newman, L. A., Korol, D. L., and Gold, P. E. (2011). Lactate produced by glycogenolysis in astrocytes regulates memory processing. PLoS ONE 6:e28427. doi: 10.1371/ journal.pone. 0028427

Nguyen, N. H., Brathe, A., and Hassel, B. (2003). Neuronal uptake and metabolism of glycerol and the neuronal expression of mitochondrial glycerol-3-phosphate dehydrogenase. J. Neurochem. 85, 831-842.

Nicholls, D. G. (2004). Mitochondrial dysfunction and glutamate excitotoxicity studied in primary neuronal cultures. Curr. Mol. Med. 4, 149-177.

Nicholls, D. G., Johnson-Cadwell, L., Vesce, S., Jekabsons, M., and Yadava, N. (2007). Bioenergetics of mitochondria in cultured neurons and their role in glutamate excitotoxicity. J. Neurosci. Res. 85, 3206-3212.

Niwa, K., Porter, V. A., Kazama, K. Cornfield, D., Carlson, G. A., and Iadecola, C. (2001). A betapeptides enhance vasoconstriction in cerebral circulation. Am. J. Physiol. Heart Circ. Physiol. 281, H2417-H2424

Niwa, K., Younkin, L., Ebeling, C., Turner, S. K., Westaway, D., Younkin, S., et al. (2000). Abeta 1-40-related reduction in functional hyperemia in mouse neocortex during somatosensory activation. Proc. Natl. Acad. Sci. U.S.A. 97, 9735-9740.

O’Hara, J. A., Hou, H., Demidenko, E., Springett, R. J., Khan, N., and Swartz, H. M. (2005). Simultaneous measurement of rat brain cortex $\mathrm{PtO} 2$ using EPR oximetry and a fluorescence fiber-optic sensor during normoxia and hyperoxia. Physiol. Meas. 26, 203-213.

Oberheim, N. A., Wang, X., Goldman, S., and Nedergaard, M. (2006). Astrocytic complexity distinguishes the human brain. Trends Neurosci. $29,547-553$. 
Ogata, K., and Kosaka, T. (2002). Structural and quantitative analysis of astrocytes in the mouse hippocampus. Neuroscience 113, 221-233.

Overstreet, L. S., Kinney, G. A., Liu, Y. B., Billups, D., and Slater, N. T. (1999). Glutamate transporters contribute to the time course of synaptic transmission in cerebellar granule cells. J. Neurosci. 19, 9663-9673.

Palaiologos, G., Hertz, L., and Schousboe, A. (1988). Evidence that aspartate aminotransferase activity and ketodicarboxylate carrier function are essential for biosynthesis of transmitter glutamate. J. Neurochem. 51, 317-320.

Panatier, A., Theodosis, D. T., Mothet, J. P., Touquet, B., Pollegioni, L., Poulain, D. A., et al. (2006). Gliaderived D-serine controls NMDA receptor activity and synaptic memory. Cell 125, 775-784.

Pannasch, U., Vargova, L., Reingruber, J., Ezan, P., Holcman, D., Giaume, C., et al. (2011). Astroglial networks scale synaptic activity and plasticity. Proc. Natl. Acad. Sci. U.S.A. 108, 8467-8472.

Pardo, B., Rodrigues, T. B., Contreras, L., Garzon, M., Llorente-Folch, I., Kobayashi, K., et al. (2011). Brain glutamine synthesis requires neuronal-born aspartate as amino donor for glial glutamate formation. J. Cereb. Blood Flow Metab. 31, 90-101.

Parfenova, H., Tcheranova, D., Basuroy, S., Fedinec, A. L., Liu, J., and Leffler, C. W. (2012). Functional role of astrocyte glutamate receptors and carbon monoxide in cerebral vasodilation response to glutamate. Am. J. Physiol. Heart Circ. Physiol. 302, H2257-H2266.

Park, L., Anrather, J., Forster, C., Kazama, K., Carlson, G. A., and Iadecola, C. (2004). Abeta-induced vascular oxidative stress and attenuation of functional hyperemia in mouse somatosensory cortex. J. Cereb. Blood Flow Metab. 24, 334-342.

Parpura, V., Basarsky, T. A., Liu, F., Jeftinija, K., Jeftinija, S., and Haydon, P. G. (1994). Glutamate-mediated astrocyteneuron signalling. Nature 369, 744-747.

Pascual, J. M., Carceller, F., Roda, J. M., and Cerdan, S. (1998). Glutamate, glutamine, and GABA as substrates for the neuronal and glial compartments after focal cerebral ischemia in rats. Stroke 29, 1048-1056. discussion: 1056-1047.
Paulson, O. B., and Newman, E. A. (1987). Does the release of potassium from astrocyte endfeet regulate cerebral blood flow? Science 237, 896-898.

Pellegri, G., Rossier, C., Magistretti, P. J., and Martin, J. L. (1996). Cloning, localization and induction of mouse brain glycogen synthase. Brain Res. Mol. Brain Res. 38, 191-199.

Pellerin, L., and Magistretti, P. J. (1994). Glutamate uptake into astrocytes stimulates aerobic glycolysis: a mechanism coupling neuronal activity to glucose utilization. Proc. Natl. Acad. Sci. U.S.A. 91, 10625-10629.

Pellerin, L., Pellegri, G., Bittar, P. G., Charnay, Y., Bouras, C., Martin, J. L., et al. (1998a). Evidence supporting the existence of an activitydependent astrocyte-neuron lactate shuttle. Dev. Neurosci. 20, 291-299.

Pellerin, L., Pellegri, G., Martin, J. L., and Magistretti, P. J. (1998b). Expression of monocarboxylate transporter mRNAs in mouse brain: support for a distinct role of lactate as an energy substrate for the neonatal vs. adult brain. Proc. Natl. Acad. Sci. U.S.A. 95, 3990-3995.

Peng, L., Gu, L., Zhang, H., Huang, X., Hertz, E., and Hertz, L. (2007). Glutamine as an energy substrate in cultured neurons during glucose deprivation. J. Neurosci. Res. 85, 3480-3486.

Peng, L., Zhang, X., and Hertz, L. (1994). High extracellular potassium concentrations stimulate oxidative metabolism in a glutamatergic neuronal culture and glycolysis in cultured astrocytes but have no stimulatory effect in a GABAergic neuronal culture. Brain Res. 663, 168-172.

Peng, X., Carhuapoma, J. R., Bhardwaj, A., Alkayed, N. J., Falck, J. R., Harder, D. R., et al. (2002). Suppression of cortical functional hyperemia to vibrissal stimulation in the rat by epoxygenase inhibitors. Am. J. Physiol. Heart Circ. Physiol. 283, H2029-H2037.

Perea, G., and Araque, A. (2007). Astrocytes potentiate transmitter release at single hippocampal synapses. Science 317, 1083-1086.

Petravicz, J., Fiacco, T. A., and McCarthy, K. D. (2008). Loss of IP3 receptor-dependent $\mathrm{Ca} 2+$ increases in hippocampal astrocytes does not affect baseline CA1 pyramidal neuron synaptic activity. J. Neurosci. 28 , 4967-4973.

Phelps, C. H. (1972). Barbiturateinduced glycogen accumulation in brain. An electron microscopic study. Brain Res. 39, 225-234.

Phillis, J. W., Ren, J., and O'Regan, M. H. (2000). Transporter reversal as a mechanism of glutamate release from the ischemic rat cerebral cortex: studies with DL-threobeta-benzyloxyaspartate. Brain Res. 868, 105-112.

Pierre, K., Magistretti, P. J., and Pellerin, L. (2002). MCT2 is a major neuronal monocarboxylate transporter in the adult mouse brain. J. Cereb. Blood Flow Metab. 22, 586-595.

Pines, G., Danbolt, N. C., Bjoras, M., Zhang, Y., Bendahan, A., Eide, L., et al. (1992). Cloning and expression of a rat brain Lglutamate transporter. Nature 360 , 464-467.

Pocai, A., Lam, T. K., Gutierrez-Juarez, R., Obici, S., Schwartz, G. J., Bryan, J., et al. (2005). Hypothalamic K(ATP) channels control hepatic glucose production. Nature 434, 1026-1031.

Poloyac, S. M., Zhang, Y., Bies, R. R., Kochanek, P. M., and Graham, S. H. (2006). Protective effect of the 20-HETE inhibitor HET0016 on brain damage after temporary focal ischemia. J. Cereb. Blood Flow Metab. 26, 1551-1561.

Porras, O. H., Loaiza, A., and Barros, L. F. (2004). Glutamate mediates acute glucose transport inhibition in hippocampal neurons. J. Neurosci. 24 , 9669-9673.

Porras, O. H., Ruminot, I., Loaiza, A. and Barros, L. F. (2008). $\mathrm{Na}(+)$ $\mathrm{Ca}(2+)$ cosignaling in the stimulation of the glucose transporter GLUT1 in cultured astrocytes. Glia $56,59-68$.

Porter, J. T., and McCarthy, K. D. (1996). Hippocampal astrocytes in situ respond to glutamate released from synaptic terminals. J. Neurosci. 16, 5073-5081.

Price, D. L., Ludwig, J. W., Mi, H., Schwarz, T. L., and Ellisman, M. H. (2002). Distribution of rSlo Ca2+activated $\mathrm{K}+$ channels in rat astrocyte perivascular endfeet. Brain Res. 956, 183-193.

Prichard, J., Rothman, D., Novotny, E., Petroff, O., Kuwabara, T., Avison, M., et al. (1991). Lactate rise detected by $1 \mathrm{H}$ NMR in human visual cortex during physiologic stimulation. Proc. Natl. Acad. Sci. U.S.A. 88, 5829-5831.

Proper, E. A., Hoogland, G., Kappen, S. M., Jansen, G. H., Rensen, M. G., Schrama, L. H., et al. (2002). Distribution of glutamate transporters in the hippocampus of patients with pharmaco-resistant temporal lobe epilepsy. Brain 125, 32-43.

Ramos, M., Del Arco, A., Pardo, B., Martinez-Serrano, A., MartinezMorales, J. R., Kobayashi, K., et al. (2003). Developmental changes in the $\mathrm{Ca} 2+$-regulated mitochondrial aspartate-glutamate carrier aralarl in brain and prominent expression in the spinal cord. Brain Res. Dev. Brain Res. 143, 33-46.

Ramos, M., Pardo, B., Llorente-Folch, I., Saheki, T., Del Arco, A., and Satrustegui, J. (2011). Deficiency of the mitochondrial transporter of aspartate/glutamate aralar/AGC1 causes hypomyelination and neuronal defects unrelated to myelin deficits in mouse brain. J. Neurosci. Res. 89, 2008-2017.

Rana, S., and Dringen, R. (2007). Gap junction hemichannel-mediated release of glutathione from cultured rat astrocytes. Neurosci. Lett. 415 45-48.

Renic, M., Klaus, J. A., Omura, T., Kawashima, N., Onishi, M., Miyata, N., et al. (2009). Effect of 20HETE inhibition on infarct volume and cerebral blood flow after transient middle cerebral artery occlusion. J. Cereb. Blood Flow Metab. 29, 629-639.

Robinson, J. S., Fedinec, A. L., and Leffler, C. W. (2002). Role of carbon monoxide in glutamate receptor-induced dilation of newborn pig pial arterioles. Am. J. Physiol. Heart Circ. Physiol. 282, H2371-H2376.

Robinson, S. R. (2000). Neuronal expression of glutamine synthetase in Alzheimer's disease indicates a profound impairment of metabolic interactions with astrocytes. Neurochem. Int. 36, 471-482.

Rodriguez, J. J., Olabarria, M. Chvatal, A., and Verkhratsky, A. (2009). Astroglia in dementia and Alzheimer's disease. Cell Death Differ. 16, 378-385.

Rossi, D. J., Brady, J. D., and Mohr, C. (2007). Astrocyte metabolism and signaling during brain ischemia. Nat. Neurosci. 10, 1377-1386.

Rothstein, J. D., Martin, L., Levey, A. I., Dykes-Hoberg, M., Jin, L., Wu, D., et al. (1994). Localization of neuronal and glial glutamate transporters. Neuron 13, 713-725.

Rouach, N., Avignone, E., Meme, W., Koulakoff, A., Venance, L., Blomstrand, F., et al. (2002). Gap junctions and connexin expression in the normal and pathological central nervous system. Biol. Cell 94, 457-475. 
Rouach, N., Koulakoff, A., Abudara, V., Willecke, K., and Giaume, C. (2008). Astroglial metabolic networks sustain hippocampal synaptic transmission. Science 322, 1551-1555.

Ruminot, I., Gutierrez, R., PenaMunzenmayer, G., Anazco, C., Sotelo-Hitschfeld, T., Lerchundi, R., et al. (2011). NBCe1 mediates the acute stimulation of astrocytic glycolysis by extracellular $\mathrm{K}+$. J. Neurosci. 31, 14264-14271.

Rutter, J., Reick, M., Wu, L. C., and McKnight, S. L. (2001). Regulation of clock and NPAS2 DNA binding by the redox state of NAD cofactors. Science 293, 510-514.

Sagar, S. M., Sharp, F. R., and Swanson, R. A. (1987). The regional distribution of glycogen in rat brain fixed by microwave irradiation. Brain Res. 417, 172-174.

San Martin, A., Ceballo, S., Ruminot, I., Lerchundi, R., Frommer, W. B., and Barros, L. F. (2013). A genetically encoded FRET lactate sensor and its use to detect the warburg effect in single cancer cells. PLoS ONE 8:e57712. doi: 10.1371/ journal.pone.0057712

Sasaki, T., Kuga, N., Namiki, S., Matsuki, N., and Ikegaya, Y. (2011). Locally synchronized astrocytes. Cereb. Cortex 21, 1889-1900.

Scemes, E., Dermietzel, R., and Spray, D. C. (1998). Calcium waves between astrocytes from $\mathrm{Cx} 43$ knockout mice. Glia 24, 65-73.

Scemes, E., and Giaume, C. (2006). Astrocyte calcium waves: what they are and what they do. Glia 54, 716-725.

Scharfman, H. E. (2007). The neurobiology of epilepsy. Curr. Neurol. Neurosci. Rep. 7, 348-354.

Scheff, S. W., Price, D. A., Schmitt, F. A., Dekosky, S. T., and Mufson, E. J. (2007). Synaptic alterations in CAl in mild Alzheimer disease and mild cognitive impairment. Neurology 68, 1501-1508.

Schild, L., Huppelsberg, J., Kahlert, S., Keilhoff, G., and Reiser, G. (2003). Brain mitochondria are primed by moderate $\mathrm{Ca} 2+$ rise upon hypoxia/reoxygenation for functional breakdown and morphological disintegration. J. Biol. Chem. 278, 25454-25460.

Schneider, U., Poole, R. C., Halestrap, A. P., and Grafe, P. (1993). Lactateproton co-transport and its contribution to interstitial acidification during hypoxia in isolated rat spinal roots. Neuroscience 53, 1153-1162.

Schousboe, A., Sickmann, H. M., Walls, A. B., Bak, L. K., and Waagepetersen,
H. S. (2010). Functional importance of the astrocytic glycogen-shunt and glycolysis for maintenance of an intact intra/extracellular glutamate gradient. Neurotox. Res. 18 94-99.

Schousboe, A., Westergaard, N., Sonnewald, U., Petersen, S. B., Huang, R., Peng, L., et al. (1993). Glutamate and glutamine metabolism and compartmentation in astrocytes. Dev. Neurosci. 15, 359-366.

Schummers, J., Yu, H., and Sur, M. (2008). Tuned responses of astrocytes and their influence on hemodynamic signals in the visual cortex. Science 320, 1638-1643.

Schurr, A. (2006). Lactate: the ultimate cerebral oxidative energy substrate? J. Cereb. Blood Flow Metab. $26,142-152$.

Schurr, A., Miller, J. J., Payne, R. S., and Rigor, B. M. (1999). An increase in lactate output by brain tissue serves to meet the energy needs of glutamate-activated neurons. J. Neurosci. 19, 34-39.

Schurr, A., Payne, R. S., Miller, J. J. and Rigor, B. M. (1997). Brain lactate, not glucose, fuels the recovery of synaptic function from hypoxia upon reoxygenation: an in vitro study. Brain Res. 744, 105-111.

Schurr, A., West, C. A., and Rigor, B. M. (1988). Lactate-supported synaptic function in the rat hippocampal slice preparation. Science 240 , 1326-1328.

Schwartz, M. W., Woods, S. C., Porte, D. Jr., Seeley, R. J., and Baskin, D. G. (2000). Central nervous system control of food intake. Nature 404, 661-671.

Scott, H. L., Pow, D. V., Tannenberg, A. E., and Dodd, P. R. (2002). Aberrant expression of the glutamate transporter excitatory amino acid transporter 1 (EAAT1) in Alzheimer's disease. J. Neurosci. 22, RC206.

Selkoe, D. J., and Schenk, D. (2003). Alzheimer's disease: molecular understanding predicts amyloidbased therapeutics. Annu. Rev. Pharmacol. Toxicol. 43, 545-584.

Senitz, D., Reichenbach, A., and Smith, T. G. Jr. (1995). Surface complexity of human neocortical astrocytic cells: changes with development, aging, and dementia. J. Hirnforsch. $36,531-537$.

Sepkuty, J. P., Cohen, A. S., Eccles, C., Rafiq, A., Behar, K., Ganel, R., et al. (2002). A neuronal glutamate transporter contributes to neurotransmitter GABA synthesis and epilepsy. J. Neurosci. 22, 6372-6379.

Shank, R. P., Bennett, G. S., Freytag, S. O., and Campbell, G. L. (1985)
Pyruvate carboxylase: an astrocytespecific enzyme implicated in the replenishment of amino acid neurotransmitter pools. Brain Res. 329, 364-367.

Shashidharan, P., Wittenberg, I., and Plaitakis, A. (1994). Molecular cloning of human brain glutamate/aspartate transporter II. Biochim. Biophys. Acta 1191, 393-396.

Shelton, M. K., and McCarthy, K. D. (2000). Hippocampal astrocytes exhibit $\mathrm{Ca} 2+$-elevating muscarinic cholinergic and histaminergic receptors in situ. J. Neurochem. 74 , 555-563.

Sheppard, C. A., Simpson, P. B., Sharp, A. H., Nucifora, F. C., Ross, C. A., Lange, G. D., et al. (1997). Comparison of type 2 inositol 1,4,5trisphosphate receptor distribution and subcellular $\mathrm{Ca} 2+$ release sites that support $\mathrm{Ca} 2+$ waves in cultured astrocytes. J. Neurochem. 68 2317-2327.

Shigetomi, E., Kracun, S., Sofroniew, M. V., and Khakh, B. S. (2010). A genetically targeted optical sensor to monitor calcium signals in astrocyte processes. Nat. Neurosci. 13, 759-766.

Shigetomi, E., Tong, X., Kwan, K. Y., Corey, D. P., and Khakh, B. S. (2012). TRPA1 channels regulate astrocyte resting calcium and inhibitory synapse efficacy through GAT-3. Nat. Neurosci. 15, 70-80.

Shimizu, H., Watanabe, E., Hiyama T. Y., Nagakura, A., Fujikawa, A. Okado, H., et al. (2007). Glial Nax channels control lactate signaling to neurons for brain $[\mathrm{Na}+]$ sensing. Neuron 54, 59-72.

Shokati, T., Zwingmann, C., and Leibfritz, D. (2005). Contribution of extracellular glutamine as an anaplerotic substrate to neuronal metabolism: a re-evaluation by multinuclear NMR spectroscopy in primary cultured neurons. Neurochem. Res. 30, 1269-1281.

Shulman, R. G., Hyder, F., and Rothman, D. L. (2001). Cerebral energetics and the glycogen shunt: neurochemical basis of functional imaging. Proc. Natl. Acad. Sci. U.S.A. 98, 6417-6422.

Sickmann, H. M., Schousboe, A., Fosgerau, K., and Waagepetersen, H. S. (2005). Compartmentation of lactate originating from glycogen and glucose in cultured astrocytes. Neurochem. Res. 30, 1295-1304.

Sickmann, H. M., Walls, A. B., Schousboe, A., Bouman, S. D. and Waagepetersen, H. S. (2009). Functional significance of brain glycogen in sustaining glutamatergic neurotransmission. J. Neurochem. 109(Suppl. 1), 80-86. Silver, I. A., Deas, J., and Erecinska, M. (1997). Ion homeostasis in brain cells: differences in intracellular ion responses to energy limitation between cultured neurons and glial cells. Neuroscience 78, 589-601.

Simard, M., Arcuino, G., Takano, T., Liu, Q. S., and Nedergaard, M. (2003). Signaling at the gliovascular interface. J. Neurosci. 23, 9254-9262.

Simpkins, A. N., Rudic, R. D., Schreihofer, D. A., Roy, S., Manhiani, M., Tsai, H. J., et al. (2009). Soluble epoxide inhibition is protective against cerebral ischemia via vascular and neural protection. Am. J. Pathol. 174, 2086-2095

Simpson, I. A., Carruthers, A., and Vannucci, S. J. (2007). Supply and demand in cerebral energy metabolism: the role of nutrient transporters. J. Cereb. Blood Flow Metab. 27, 1766-1791.

Simpson, J. E., Ince, P. G., Lace, G., Forster, G., Shaw, P. J., Matthews, F. et al. (2010). Astrocyte phenotype in relation to Alzheimer-type pathology in the ageing brain. Neurobiol. Aging 31, 578-590.

Small, G. W., Ercoli, L. M., Silverman, D. H., Huang, S. C., Komo, S., Bookheimer, S. Y., et al. (2000). Cerebral metabolic and cognitive decline in persons at genetic risk for Alzheimer's disease. Proc. Natl. Acad. Sci. U.S.A. 97, 6037-6042.

Smith, C. D., Carney, J. M., StarkeReed, P. E., Oliver, C. N., Stadtman, E. R., Floyd, R. A., et al. (1991). Excess brain protein oxidation and enzyme dysfunction in normal aging and in Alzheimer disease. Proc. Natl. Acad. Sci. U.S.A. 88, 10540-10543.

Sontheimer, H. (1994). Voltagedependent ion channels in glial cells. Glia 11, 156-172.

Sontheimer, H., and Waxman, S. G. (1993). Expression of voltageactivated ion channels by astrocytes and oligodendrocytes in the hippocampal slice. J. Neurophysiol. 70, 1863-1873.

Sorg, O., and Magistretti, P. J. (1992). Vasoactive intestinal peptide and noradrenaline exert long-term control on glycogen levels in astrocytes: blockade by protein synthesis inhibition. J. Neurosci. 12, 4923-4931.

Steele, M. L., and Robinson, S. R. (2012). Reactive astrocytes give neurons less support: implications for Alzheimer's disease. Neurobiol. Aging 33, 423.el-e13. 
Stobart, J. L., Lu, L., Anderson, H. D., Mori, H., and Anderson, C. M. (2013). Astrocyte-induced cortical vasodilation is mediated by $\mathrm{D}$ serine and endothelial nitric oxide synthase. Proc. Natl. Acad. Sci. U.S.A. 110, 3149-3154.

Storck, T., Schulte, S., Hofmann, K., and Stoffel, W. (1992). Structure, expression, and functional analysis of a $\mathrm{Na}(+)$-dependent glutamate/aspartate transporter from rat brain. Proc. Natl. Acad. Sci. U.S.A. 89, 10955-10959.

Straub, S. V., Bonev, A. D., Wilkerson, M. K., and Nelson, M. T. (2006). Dynamic inositol trisphosphatemediated calcium signals within astrocytic endfeet underlie vasodilation of cerebral arterioles. J. Gen. Physiol. 128, 659-669.

Suadicani, S. O., Brosnan, C. F., and Scemes, E. (2006). P2X7 receptors mediate ATP release and amplification of astrocytic intercellular $\mathrm{Ca} 2+$ signaling. J. Neurosci. 26, 1378-1385.

Suematsu, M., Goda, N., Sano, T., Kashiwagi, S., Egawa, T., Shinoda, Y., et al. (1995). Carbon monoxide: an endogenous modulator of sinusoidal tone in the perfused rat liver. J. Clin. Invest. 96, 2431-2437.

Suematsu, M., Kashiwagi, S., Sano, T., Goda, N., Shinoda, Y., and Ishimura, Y. (1994). Carbon monoxide as an endogenous modulator of hepatic vascular perfusion. Biochem. Biophys. Res. Commun. 205, 1333-1337.

Suh, M., Ma, H., Zhao, M., Sharif, S., and Schwartz, T. H. (2006). Neurovascular coupling and oximetry during epileptic events. Mol. Neurobiol. 33, 181-197.

Suh, S. W., Bergher, J. P., Anderson, C. M., Treadway, J. L., Fosgerau, K., and Swanson, R. A. (2007). Astrocyte glycogen sustains neuronal activity during hypoglycemia: studies with the glycogen phosphorylase inhibitor CP-316, 819 ([R-R*, S*]-5chloro-N-[2-hydroxy-3-(methoxy methylamino)-3-oxo-1-(phenylmet hyl)propyl]-1H-indole-2-carboxa mide). J. Pharmacol. Exp. Ther. 321, 45-50.

Sun, G. Y., Xu, J., Jensen, M. D., Yu, S., Wood, W. G., Gonzalez, F. A., et al. (2005). Phospholipase A2 in astrocytes: responses to oxidative stress, inflammation, and $G$ protein-coupled receptor agonists. Mol. Neurobiol. 31, 27-41.

Sun, J., Druhan, L. J., and Zweier, J. L. (2008). Dose dependent effects of reactive oxygen and nitrogen species on the function of neuronal nitric oxide synthase. Arch. Biochem. Biophys. 471, 126-133.

Sun, W., McConnell, E., Pare, J. F., $\mathrm{Xu}, \mathrm{Q}$., Chen, M., Peng, W., et al. (2013). Glutamate-dependent neuroglial calcium signaling differs between young and adult brain. Science 339, 197-200.

Suzuki, A., Stern, S. A., Bozdagi, O. Huntley, G. W., Walker, R. H., Magistretti, P. J., et al. (2011). Astrocyte-neuron lactate transport is required for long-term memory formation. Cell 144, 810-823.

Swanson, R. A., and Choi, D. W. (1993). Glial glycogen stores affect neuronal survival during glucose deprivation in vitro. J. Cereb. Blood Flow Metab. $13,162-169$.

Swanson, R. A., Sagar, S. M., and Sharp F. R. (1989). Regional brain glycogen stores and metabolism during complete global ischaemia. Neurol. Res. 11, 24-28.

Takano, T., Han, X., Deane, R., Zlokovic, B., and Nedergaard, M. (2007). Two-photon imaging of astrocytic $\mathrm{Ca} 2+$ signaling and the microvasculature in experimental mice models of Alzheimer's disease. Ann. N.Y. Acad. Sci. 1097, 40-50.

Takano, T., Tian, G. F., Peng, W., Lou, N., Libionka, W., Han, X. et al. (2006). Astrocyte-mediated control of cerebral blood flow. Nat. Neurosci. 9, 260-267.

Takata, N., Mishima, T., Hisatsune, C., Nagai, T., Ebisui, E., Mikoshiba, K., et al. (2011). Astrocyte calcium signaling transforms cholinergic modulation to cortical plasticity in vivo. J. Neurosci. 31, 18155-18165.

Tanaka, K., Watase, K., Manabe, T., Yamada, K., Watanabe, M., Takahashi, K., et al. (1997). Epilepsy and exacerbation of brain injury in mice lacking the glutamate transporter GLT-1. Science 276, 1699-1702.

Tanaka, Y., Omura, T., Fukasawa, M., Horiuchi, N., Miyata, N., Minagawa, T., et al. (2007) Continuous inhibition of 20-HETE synthesis by TS-011 improves neurological and functional outcomes after transient focal cerebral ischemia in rats. Neurosci. Res. 59, 475-480.

Tekkok, S. B., Brown, A. M. Westenbroek, R., Pellerin, L. and Ransom, B. R. (2005). Transfer of glycogen-derived lactate from astrocytes to axons via specific monocarboxylate transporters supports mouse optic nerve activity. J. Neurosci. Res. 81, 644-652.
Thomas, T., Thomas, G., McLendon, C., Sutton, T., and Mullan, M. (1996). beta-Amyloidmediated vasoactivity and vascular endothelial damage. Nature 380 , 168-171.

Tian, G. F., Azmi, H., Takano, T., Xu, Q., Peng, W., Lin, J., et al. (2005). An astrocytic basis of epilepsy. Nat. Med. 11, 973-981.

Tong, G., and Jahr, C. E. (1994). Block of glutamate transporters potentiates postsynaptic excitation. Neuron 13, 1195-1203.

Tsacopoulos, M., and Magistretti, P. J. (1996). Metabolic coupling between glia and neurons. J. Neurosci. 16 877-885.

Udosen, I. T., Jiang, H., Hercule, H. C. and Oyekan, A. O. (2003). Nitric oxide-epoxygenase interactions and arachidonate-induced dilation of rat renal microvessels. Am. J. Physiol. Heart Circ. Physiol. 285, H2054-H2063.

Uhlhaas, P. J., and Singer, W. (2006). Neural synchrony in brain disorders: relevance for cognitive dysfunctions and pathophysiology. Neuron 52, 155-168.

Vannucci, S. J., Maher, F., and Simpson, I. A. (1997). Glucose transporter proteins in brain: delivery of glucose to neurons and glia. Glia 21, 2-21.

Ventura, R., and Harris, K. M. (1999) Three-dimensional relationships between hippocampal synapses and astrocytes. J. Neurosci. 19, 6897-6906.

Voloboueva, L. A., Suh, S. W., Swanson, R. A., and Giffard, R. G. (2007) Inhibition of mitochondrial function in astrocytes: implications for neuroprotection. J. Neurochem. 102 1383-1394.

Voutsinos-Porche, B., Bonvento, G. Tanaka, K., Steiner, P., Welker, E., Chatton, J. Y., et al. (2003). Glial glutamate transporters mediate a functional metabolic crosstalk between neurons and astrocytes in the mouse developing cortex. Neuron 37, 275-286.

Waagepetersen, H. S., Qu, H. Schousboe, A., and Sonnewald, U. (2001). Elucidation of the quantitative significance of pyruvate carboxylation in cultured cerebellar neurons and astrocytes. J. Neurosci. Res. 66, 763-770.

Wallraff, A., Kohling, R., Heinemann, U., Theis, M., Willecke, K., and Steinhauser, C. (2006). The impact of astrocytic gap junctional coupling on potassium buffering in the hippocampus. J. Neurosci. 26 5438-5447.

Walz, W., and Mukerji, S. (1988) Lactate release from cultured astrocytes and neurons: a comparison. Glia 1, 366-370.

Walz, W., and Mukerji, S. (1990). Simulation of aspects of ischemia in cell culture: changes in lactate compartmentation. Glia 3, 522-528.

Warkentin, S., and Passant, U. (1997). Functional imaging of the frontal lobes in organic dementia. Regional cerebral blood flow findings in normals, in patients with frontotemporal dementia and in patients with Alzheimer's disease, performing a word fluency test. Dement. Geriatr. Cogn. Disord. 8, 105-109.

Watase, K., Hashimoto, K., Kano, M., Yamada, K., Watanabe, M., Inoue, Y., et al. (1998). Motor discoordination and increased susceptibility to cerebellar injury in GLAST mutant mice. Eur. J. Neurosci. 10, 976-988.

Wender, R., Brown, A. M., Fern, R., Swanson, R. A., Farrell, K., and Ransom, B. R. (2000). Astrocytic glycogen influences axon function and survival during glucose deprivation in central white matter. J. Neurosci. 20, 6804-6810.

Wilhelmus, M. M., Otte-Holler, I., Van Triel, J. J., Veerhuis, R., Maat-Schieman, M. L., Bu, G., et al. (2007). Lipoprotein receptor-related protein-1 mediates amyloid-beta-mediated cell death of cerebrovascular cells. Am. J. Pathol. 171, 1989-1999.

Wolff, J. R., Stuke, K., Missler, M. Tytko, H., Schwarz, P., Rohlmann, A., et al. (1998). Autocellular coupling by gap junctions in cultured astrocytes: a new view on cellular autoregulation during process formation. Glia 24, 121-140.

Wu, L., Cao, K., Lu, Y., and Wang, R. (2002). Different mechanisms underlying the stimulation of $\mathrm{K}(\mathrm{Ca})$ channels by nitric oxide and carbon monoxide. J. Clin. Invest. 110 691-700.

Wyss, M. T., Jolivet, R., Buck, A., Magistretti, P. J., and Weber, B. (2011). In vivo evidence for lactate as a neuronal energy source. J. Neurosci. 31, 7477-7485.

Xi, Q., Tcheranova, D., Basuroy, S. Parfenova, H., Jaggar, J. H., and Leffler, C. W. (2011). Glutamateinduced calcium signals stimulate $\mathrm{CO}$ production in piglet astrocytes. Am. J. Physiol. Heart Circ. Physiol. 301, H428-H433.

Xi, Q., Umstot, E., Zhao, G., Narayanan, D., Leffler, C. W. and Jaggar, J. H. (2010). Glutamate regulates $\mathrm{Ca} 2+$ signals in smooth muscle cells of newborn piglet 
brain slice arterioles through astrocyte- and heme oxygenasedependent mechanisms. Am. J. Physiol. Heart Circ. Physiol. 298, H562-H569.

Ye, Z. C., Wyeth, M. S., BaltanTekkok, S., and Ransom, B. R. (2003). Functional hemichannels in astrocytes: a novel mechanism of glutamate release. J. Neurosci. 23, 3588-3596.

Yu, A. C., Drejer, J., Hertz, L., and Schousboe, A. (1983). Pyruvate carboxylase activity in primary cultures of astrocytes and neurons. J. Neurochem. 41, 1484-1487.
Zhang, W., Koerner, I. P., Noppens, R., Grafe, M., Tsai, H. J., Morisseau, C., et al. (2007). Soluble epoxide hydrolase: a novel therapeutic target in stroke. J. Cereb. Blood Flow Metab. 27, 1931-1940.

Zhang, W., Otsuka, T., Sugo, N., Ardeshiri, A., Alhadid, Y. K., Iliff, J. J., et al. (2008). Soluble epoxide hydrolase gene deletion is protective against experimental cerebral ischemia. Stroke 39, 2073-2078.

Zhang, Y., Pertens, E., and Janssen, L. J. (2005). 8-isoprostaglandin $\mathrm{E}(2)$ activates $\mathrm{Ca}(2+)$-dependent $\mathrm{K}(+)$ current via cyclic AMP signaling pathway in murine renal artery. Eur. J. Pharmacol. 520, 22-28.

Zonta, M., Angulo, M. C., Gobbo, S., Rosengarten, B., Hossmann, K. A., Pozzan, T., et al. (2003). Neuronto-astrocyte signaling is central to the dynamic control of brain microcirculation. Nat. Neurosci. 6, 43-50.

Conflict of Interest Statement: The authors declare that the research was conducted in the absence of any commercial or financial relationships that could be construed as a potential conflict of interest.
Received: 30 January 2013; accepted: 26 March 2013; published online: 10 April 2013.

Citation: Stobart JL and Anderson CM (2013) Multifunctional role of astrocytes as gatekeepers of neuronal energy supply. Front. Cell. Neurosci. 7:38. doi: 10.3389/ fncel.2013.00038

Copyright (c) 2013 Stobart and Anderson. This is an open-access article distributed under the terms of the Creative Commons Attribution License, which permits use, distribution and reproduction in other forums, provided the original authors and source are credited and subject to any copyright notices concerning any third-party graphics etc. 